\title{
Turning Everyday Activities into Play: Building Relationships and Fostering Connections for Adopted Children and Children in Foster Care
}

\author{
Marissa E. Siu \\ University of St. Augustine for Health Sciences \\ DOI: https://doi.org/10.46409/sr.PYIC7241
}

Follow this and additional works at: https://soar.usa.edu/capstones

Part of the Child Psychology Commons, Occupational Therapy Commons, and the Social Work Commons

\section{Recommended Citation}

Siu, M. E. (2020). Turning Everyday Activities into Play: Building Relationships and Fostering Connections for Adopted Children and Children in Foster Care. [Doctoral project, University of St Augustine for Health Sciences].SOAR @ USA: Student Capstone Projects Collection. https://doi.org/10.46409/sr.PYIC7241

This Capstone is brought to you for free and open access by the Student Research at SOAR @ USA. It has been accepted for inclusion in Student Capstone Projects by an authorized administrator of SOAR @ USA. For more information, please contact soar@usa.edu, erobinson@usa.edu. 


\title{
Turning Everyday Activities into Play: Building Relationships and Fostering Connections
} for Adopted Children and Children in Foster Care

\author{
Marissa E. Siu \\ Department of Occupational Therapy, University of St. Augustine for Health Sciences
}

A Capstone Presented in Partial Fulfillment of the Requirement for the Degree of DOCTOR OF OCCUPATIONAL THERAPY

University of St. Augustine for Health Sciences

September 2020 
Turning Everyday Activities into Play: Building Relationships and Fostering Connections

\title{
for Adopted Children and Children in Foster Care
}

\author{
Marissa E. Siu \\ Department of Occupational Therapy, University of St. Augustine for Health Sciences \\ has been approved \\ Month, Year
}

APPROVED:

\author{
Susan MacDermott, OTD, OTR/L, Doctoral Coordinator \\ Becki Cohill, OTD, OTR/L, Doctoral Coordinator \\ Erin Schwier, EdD, OTD, OTR/L, Program Director
}

ACCEPTED AND SIGNED:

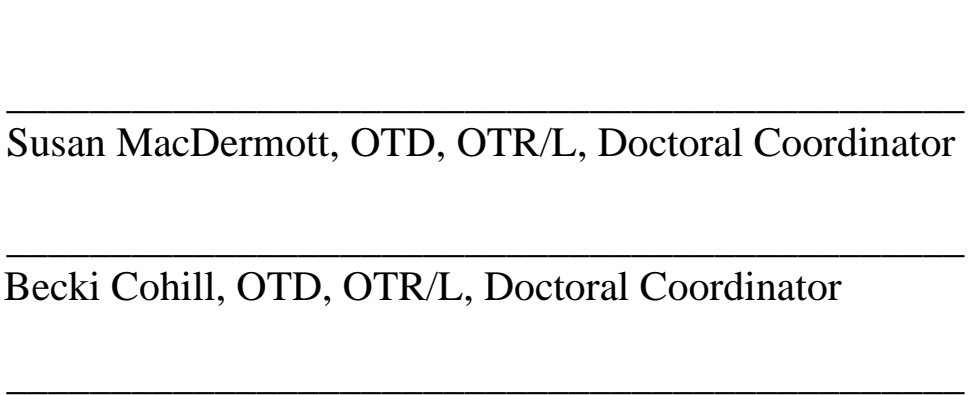

Erin Schwier, EdD, OTD, OTR/L, Program Director 


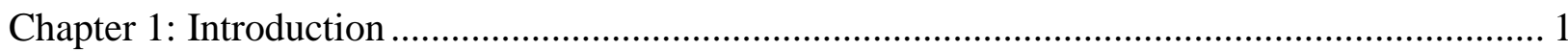

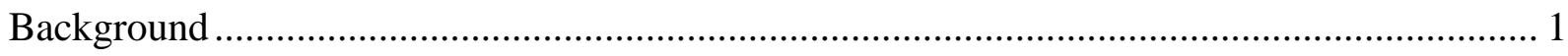

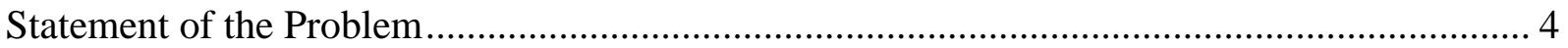

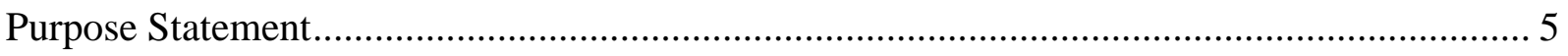

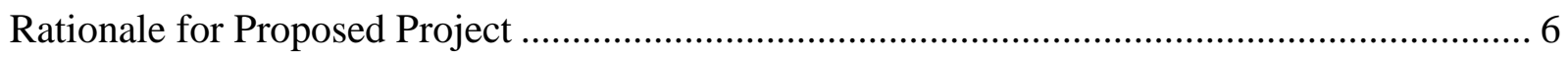

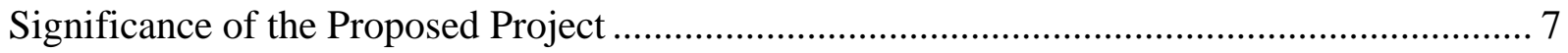

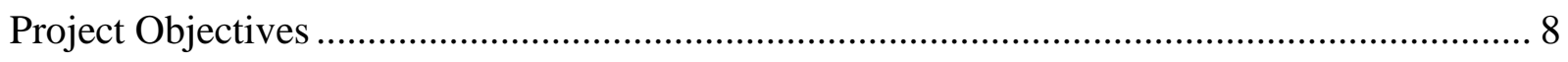

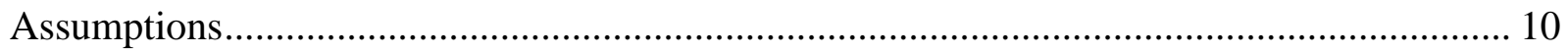

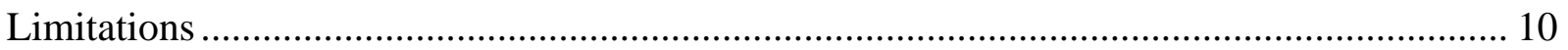

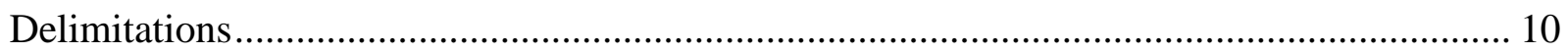

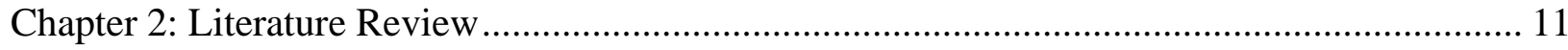

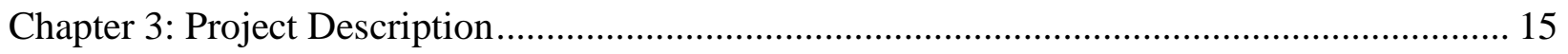

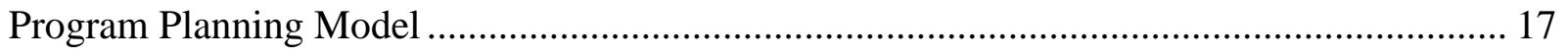

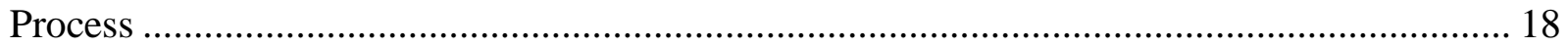

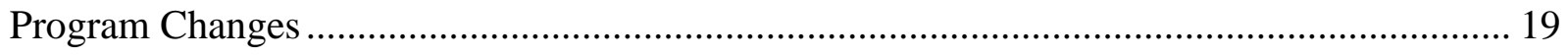

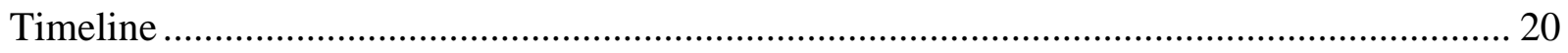

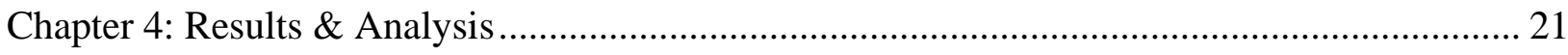

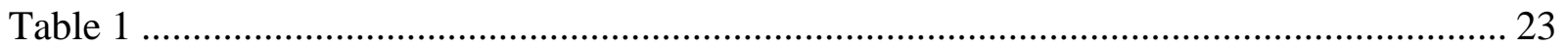




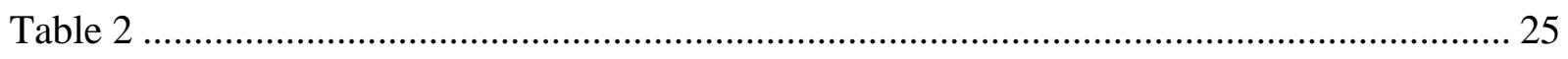

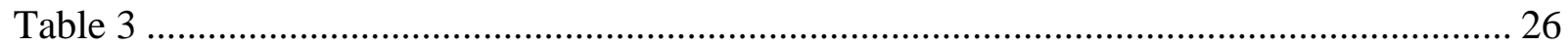

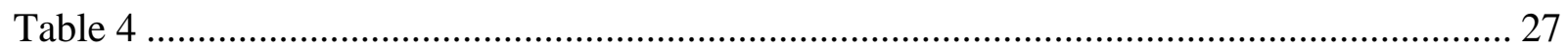

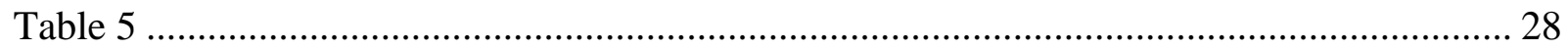

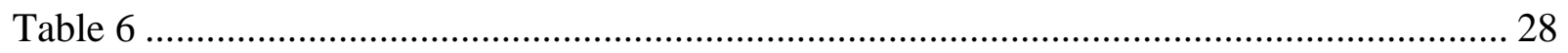

Chapter 5: Discussion and Conclusion ............................................................................ 29

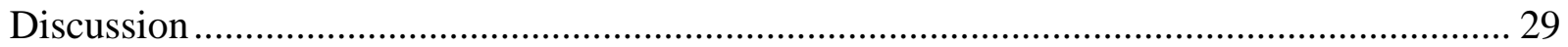

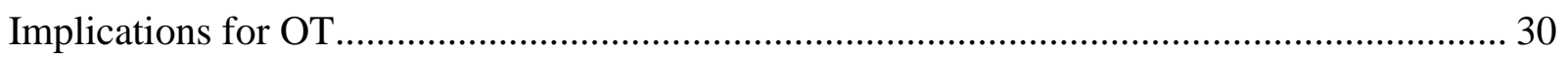

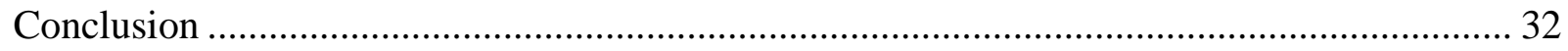

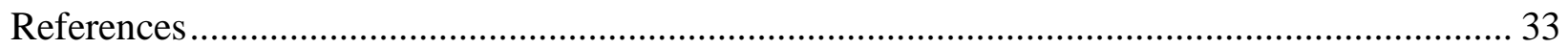

Appendix A - Survey Questions for Community Members on Home Guide ........................... 37

Appendix B - Turning Everyday Activities into Play - Home Guide ................................... 38

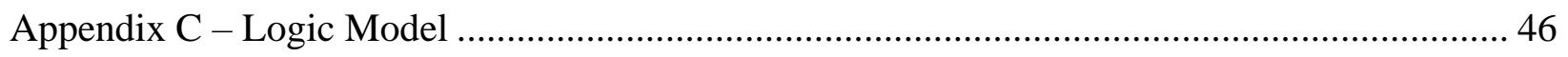

Appendix D - Sample Interview Questions for Adoptive and Foster Families ....................... 47 
Copyright () Marissa E. Siu, 2020 all rights reserved 


\section{Turning Everyday Activities into Play: Building Relationships and Fostering Connections for Adopted Children and Children in Foster Care}

\section{Chapter 1: Introduction}

The purpose of this proposal is to outline the vision for a capstone project focused on program development for community members that work children in foster care. The aim of this project is to help community members gain the knowledge and skills that will aid in the development of children in foster care through the use of occupation-based programming.

\section{Background}

Foster care provides a temporary living situation for children whose biological parent(s) are unable to care for the basic needs of a child (American Occupational Therapy Association [AOTA], 2015). A child will be temporarily removed from the parents' care and placed in foster care until the child is able to return home safely or is permanently placed with a family member or adoptive family (AOTA, 2017). As of September 30, 2018, there were over 430,000 children in foster care with over 195,000 children waiting to be adopted (U.S. Department of Health and Human Services, 2019).

A child can enter the foster system at any age ranging from birth to 20 years. However, $19 \%$ of children entering foster care are less than one year of age (U.S. Department of Health and Human Services, 2018). A child can enter foster care for a number of reasons. The most common reasons are "neglect, physical or emotional abuse, parental substance abuse, and caretaker's inability to provide or cope" (Lickteig \& Lickteig, 2019, p.1). The initial trauma a foster child experiences is from the initial abuse or neglect from their birth parent or parents (Lickteig \& Lickteig, 2019). The separation from the birth family can also be traumatic for a 
child. The results of childhood trauma often lead to significantly higher rates of behavioral problems and developmental disorders (Child Welfare Information Gateway, 2015).

Research has shown that abuse is often associated with low self-esteem, hostility, and aggression in individuals who have suffered maltreatment during their childhood (Liu et al., 2018). Depression and psychological distress are additional lasting effects of abuse (Liu et al., 2018). The consequences of abuse are long-lasting and are often carried by a child through adolescence and into adulthood. These consequences often result in insecure attachment and are extremely difficult to change after abuse as they often lead to a "negative attitude toward self and others" (Liu et al., 2018, p. 794). Although there is a considerable amount of research on the effects of childhood trauma and abuse, very little programming exists to help a child cope with the consequences of childhood trauma.

Current programs and trainings for foster parents and potential foster parents vary by state (Hebert \& Kulkin, 2017). Many trainings only fulfill the minimum requirement to certify a family to take a child into their home (Herbert \& Kulkin, 2017). The program discussed by Hebert and Kulkin (2017) was developed based on the expressed needs of foster parents. Herbert and Kulkin found that the top expressed needs of foster parents are how to manage challenging behaviors, how to help a child adjust to a foster home, and how to prevent foster care burnout as parents. The behavioral and emotional issues that a foster child experiences often results in added stress that is put on foster parents. Caregiver burnout and illness are very common issues that foster parents face while caring for a foster child (Miller, Green, \& Lambros, 2019).

Occupational therapists can provide occupational therapy services to foster care children in a variety of settings such as at school, in the home, or in the community (Lynch et al., 2017). The role of occupational therapy within the foster care system is to promote participation in 
meaningful occupations to help develop the skills necessary for "independence in activities of daily living, instrumental activities of daily living, play, leisure, and overall wellness satisfaction in independent living" (Lynch et al., 2017, p.2).

Being in the foster care system does not automatically qualify a child for occupational therapy services. Often, a child needs to have a disability such as a developmental or learning disability in order to receive occupational therapy services. In the school setting, occupational therapy services are determined through the use of the Individualized Education Program (IEP) (AOTA, 2016). If a child is unable to receive a "free, appropriate public education in the least restrictive environment", an occupational therapist will collaborate with other IEP team members to determine which "services, supports, modifications, and accommodations" are necessary for the student (AOTA, 2016, p. 2).

Other barriers such as financial aspects can also prevent a foster child from receiving occupational therapy services. While foster parents do receive some financial assistance for taking in a foster child, the amount of money they receive varies greatly depending on the state and foster agency. Additionally, the stipend that foster parents receive is intended to offset the cost of everyday items such as food, housing, and clothing. According to the Child Welfare Information Gateway (n.d.), foster parents are also responsible for everyday financial obligations. These financial obligations may include child care or participation in recreational sports.

Insurance can also be a barrier for a foster child to receive occupational therapy services. All children in foster care qualify for Medicaid insurance through the federal and state governments (Child Welfare Information Gateway, n.d.). Occupational therapy is a covered service under Medicaid but is classified as optional rather than mandatory (AOTA, 2020). 
Because it is optional, it depends on the state the child resides in to determine whether occupational therapy services will be covered by Medicaid. If Medicaid does not cover occupational therapy services, a foster parent may have to pay out of pocket for a child in foster care to receive occupational therapy services.

The effects of childhood trauma often result in "adverse outcomes including emotional, psychosocial, cognitive, and functional impairments" (Farias et al., 2019, p.228). These outcomes can negatively impact a child and can result in long-term impairments that affect a child not only at a young age but last through adolescence and into adulthood. The adverse outcomes of childhood trauma can negatively impact a child's occupational performance in meaningful activities. These challenges that a foster child experiences often affects their relationships with others, their occupations, and their overall development.

Within the scope of occupational therapy, occupations are various life activities that an individual engages in (AOTA, 2014). For a child, the occupation of play is what helps a child grow and learn (AOTA, 2020). Occupational therapists utilize play in practice to support the growth and development of children. Occupational therapists have expertise in child development and understand the impact childhood illness has on growth and development (AOTA, 2014).

\section{Statement of the Problem}

The problem with current programing for children in foster care is that training is inconsistent for those individuals who are not foster parents. There are some programs for teachers and school personnel that focus on mental health and overall well-being for children (Bazyk, 2014). Programming available for community members that want to aid in the development of children in foster care is limited. Community members such as teachers and 
school personnel, family members, respite providers, and recreational and daycare providers can all help support the development of a foster child.

This program development is needed not only because of the inconsistent training available for community members but also because the number of children in foster care is continuously growing. Community members should be trained and made aware of the effects of childhood trauma. Community members should also be trained to support the development of a foster child who has been exposed to childhood trauma.

Additionally, the current programming rarely incorporates the occupation of play and can be enhanced by utilizing an occupational therapy lens. Occupational therapists understand child development and how to utilize occupations to help a child grow and learn.

\section{Purpose Statement}

This project aims to develop a training program for community members to support the development of children in foster care through the use of play. In occupational therapy practice, the occupation of play can be used as a tool to foster a child's development. Children use play to learn about their surroundings and "develop physical coordination, emotional maturity, social skills to interact with other children, and self-confidence to try new experiences and explore new environments" (AOTA, 2012). For a child, being in the foster care system is a very challenging moment in their life. Play can help "bolster a youth's sense of self-efficacy and reduce stress, especially at challenging moments" (Shea \& Siu, 2016, p. 276). The goal of this program is to first educate the community members on the needs of children in foster care due to the trauma these children experience at a young age. The project will also provide information and suggestions on how to support a child's developmental needs through structured play activities. 
And lastly, the project will provide examples of specific play activities that can be used to support a child's development.

\section{Rationale for Proposed Project}

This project needs to be done in order to meet the developmental needs of this underserved population. Through this project, the aim is to create a program that will provide support and training for community members who are not familiar with the developmental needs of children in foster care. This program will be beneficial for a foster child's development while also providing additional support for foster parents. In the end, this project will enable a foster child to continue to grow and develop while adapting to the changes they are experiencing as they navigate through the foster care system.

The concept and importance of facilitating growth and development for a child is highlighted in Llorens' 1970 theory, The Developmental Theory of Occupational Therapy. According to Llorens, by facilitating growth, an occupational therapist will assist a child in achieving mastery of life tasks by considering the physical, neurophysiological, psychosocial, psychodynamic, and social-cultural aspects of the child throughout all stages of development (La Corte, 2008). Utilizing this framework, the child's growth will be facilitated by an adult through the participation in a variety of sensori-motor activities that build on underlying skills that are essential for child development (La Corte, 2008). Llorens believes that the experiences an individual has within the environment of the family promotes early growth and development (1970). As a child ages, influences from "extended family, community, social and civic groups assist in the growth process" (La Corte, 2008, p.206). When children experience trauma either physical or psychological in childhood, their growth and development is interrupted. 
Occupational therapists can close these gaps that children may have in their growth and development using skilled application of activities (La Corte, 2008).

Another model that will be used in this program development process is Kielhofner's Model of Human Occupation (MOHO). MOHO is the most commonly used model both nationally and internationally that is occupation-focused (Lee et al., 2012). The use of MOHO is important in order to remain client-centered by incorporating motivational activities that allow an individual to relate to and prioritize a client's needs (Kielhofner, 2008). Research has shown that by utilizing MOHO in treatment planning and monitoring, the client's overall satisfaction with occupational therapy services is enhanced (Lee et al., 2012). Community members will be utilizing structured play activities in this program that are enjoyable and motivating for children in foster care. Community members will be provided with ideas and suggestions on how to tailor activities while considering the specific interests and needs of the child. Additionally, information will be gathered from the community members to find out what their goals are for this program in order to incorporate motivating factors for them as well. By utilizing MOHO in this program, relevant interventions will be incorporated while also setting goals that are clientcentered to ensure the best overall outcome of the program.

\section{Significance of the Proposed Project}

Entering the foster care system and any time spent in foster care can be a difficult time in a child's life, Children in foster care experience a number of challenges and emotions due to their separation from their birth parents (Cox, 2013). Foster parents are encouraged to seek support from other parents through meetings and events hosted by organizations that provide support groups for kinship, foster, and adoptive parents. In the state of California, there are 79 organizations that provide these support services for foster parents (Child Welfare Information 
Gateway, n.d.). In order to attend support group meetings and sessions, foster parents often seek out childcare services or are provided childcare services by the organization. Many of these childcare services provide a place for the child to play and interact with other children while being supervised by an adult. These services often provide toys and activities for children to participate in. However, the supervising adult typically does not have the training or knowledge to aid in the child's development.

This program will be directed at the community members who frequently work or interact with children in foster care either on a professional or personal level. By developing this program, foster care children will still have the opportunity to interact and play with peers but will do so in a way that incorporates occupation which will help develop essential life skills while also helping overall development. The knowledge gained through this program will allow any community member to create activities that will help a foster child's development.

Through this program, a consultative role will be provided for community members by providing guidance, advice, and suggestions to best support foster child development. Consultation has become more prominent in the field of occupational therapy. Program consultation will be used in this program as this is commonly associated with new program development (Dudgeon \& Greenberg, 1998). This program will not only help children in foster care but will also increase current programming that is available to community members.

\section{Project Objectives}

I. Conduct a literature review to learn about gaps in current programming for children in foster care.

II. To identify the developmental needs related to occupational participation of children in foster care due to the childhood trauma experienced at a young age. 
III. To identify common play activities that are used to aid in child development in occupational therapy.

IV. To create play activities tailored specifically to aid in the development of a child in foster care.

V. To create a program that educates and trains community members on the needs of children in foster care and how to structure play activities in a way that will support child development.

VI. To measure the understanding of community members on this program directed at child development for children in foster care.

VII. To measure the receptiveness of community members incorporating this training program into their childcare services.

\section{Definition of Terms}

For this capstone project, community members refer to any individual that interacts with children in foster care that is not a foster parent. Any child who is separated from his or her birth parents and placed in temporary custody of a foster parent or family member is a child in foster care. Play is a child's major occupation which can be classified as any "organized activity that provides enjoyment, entertainment, amusement, or diversion” (Parham \& Fazio, 2008, p.448). Structured play refers to a physical activity that is planned and designed with a specific skill development goal in mind (Tortella et al., 2019). Unstructured play is referred to as free play or active play and is a form of physical activity that is freely chosen and that a child participates in an unstructured manner (Tortella et al., 2019). 


\section{Assumptions}

This capstone project makes the assumption that children in foster care have disruptions in their development due to the childhood trauma experienced at a young age. It is also assumed that community members do not have the training or knowledge to support the development of children in foster care and that they want to enhance their training and knowledge to support the development of children in foster care . Lastly, although caregiver burnout and burden are frequently discussed with foster parents, it is assumed that foster care burden results in foster parents needing assistance from community members to support the development of a foster child.

\section{Limitations}

Limitations of the capstone project include a sample size that is dependent on the voluntary involvement of foster parents and community members. The capstone experience will take place at an outpatient pediatric clinic which will likely result in having more voluntary involvement of foster parents than community members. Another limitation is that the program will occur during the Summer 2020 trimester which may limit the number of children in foster care receiving services at the pediatric clinic as some children may only receive school-based therapy services that are not provided during the summer months. Finally, participants will only be gathered from one outpatient pediatric clinic which may result in this program not being applicable to all children in foster care of different areas.

\section{Delimitations}

There are a few delimitations to this capstone project. First, as the capstone experience for this project will take place in one outpatient clinic in California, information gathered by foster parents and community members may not be applicable to other states or regions. Second, 
due to the wide age range of children in foster care, play activities suggested will need to be altered to fit specific age ranges. Finally, community members may work with children in foster care in a variety of settings. The structured play activities discussed and taught to community members will change depending on the intended setting of use.

\section{Chapter 2: Literature Review}

The foster care population is continuously growing. Children in foster care experience trauma at a young age and the effects of trauma often last a lifetime. Trauma impacts a child's overall well-being and often makes everyday activities a challenge. The literature shows that childhood trauma often results in a child having problems with negative behaviors both at home and in school. Not only are negative behaviors a common issue, but the literature has also shown that trauma can often have negative effects on a foster child's overall development. While training is emerging and evolving for foster parents and teachers, there is still a lack of training available to community members. Community members can help support the development of a foster child with the proper education.

\section{The Impacts of Foster Care}

Children entering foster care often experience challenges with their social, academic, and mental health due to the trauma experienced at a young age (Miller et al., 2019). Research has shown that the effects of childhood trauma can greatly impact a child's life through adolescence and into adulthood. Childhood trauma has been linked to poor interpersonal relationships, poor coping strategies, and an increased likelihood to suffer from depression (Liu et al., 2018). Additionally, childhood trauma often results in a child having difficulty handling their emotions, sensations, and stress (AOTA, 2015). As a result, foster parents often report the need for additional support and training on problematic behaviors (Greeno et al., 2016). 
These effects of childhood trauma can impact a child at home, school, and in the community. Literature has shown the difficulty children in foster care have in the school setting. It has been found that children in foster care frequently have difficulty concentrating in the classroom setting, getting along with others, and often have emotional instability, which often results in children having trouble with class and homework (Cox, 2013). In addition, some school personnel have reported that they are not fully prepared or supported to work with children in foster care (Cox, 2013). Some programming is already in place for school personnel to learn more about the needs of children in foster care in the school setting.

\section{Current Programming}

Theraplay is commonly used by parents of children in foster care to meet the adolescent's attachment needs through the Theraplay model (Robinson et al., 2009). Theraplay utilizes the occupation of play to help families learn how to form "secure well regulated relationships with their child" (Robinson et al., 2009, p. 292). Theraplay has been utilized in a variety of settings and has been successful in creating positive behavioral changes and relationships between families. The focus of Theraplay is on the relationship between a child and a caregiver and the child's individual developmental needs (Robinson et al., 2009).

The Trust Based Relational Intervention (TRBI) is a program that aims to correct a child's challenging behaviors with healthy behaviors (Howard et al., 2014). TRBI has the guiding principles of empowering, connection, and correcting to provide trauma-informed intervention for children (Howard et al., 2014). The TRBI also uses play to teach proactive strategies that help a child "self-regulate and use appropriate behaviors when challenging situations occur" (Howard et al., 2014, p. 50). Howard et al. (2014) utilized TRBI for families in post-adoption services and found that parents have the ability to be important change agents in 
the lives of their children. Howard et al. (2014) found that the TRBI provides families with the knowledge on how to address and overcome challenges to prevent adoption disruption.

When looking at programming for foster parents, it varies depending on the state the parent is in. Some states only require as few as 4 hours of training while others require a minimum of 30 hours (Greeno et al., 2016). While all foster parents receive training, the literature shows that many foster parents feel that foster agencies do not provide enough training, support, or information related to the foster care system or their foster child specifically (Greeno et al., 2016). As mentioned earlier, negative behaviors are often problems that school personnel and foster parents observe.

In a study by Cox (2013), the Keeping Foster and Kinship Parents Trained and Supported intervention (KEEP) was implemented to look at child behavioral change and permanency and placement stability. The KEEP intervention consists of a group of 7-12 foster/kinship parents who meet weekly with trained group leaders ("What is KEEP?, n.d.). Two group leaders tailor each weekly session to the group's specific expressed needs ("What is KEEP?, n.d.). Through KEEP, some skills that parents learn are how to reinforce preferred behaviors, build cooperation, and how to manage emotions ("What is KEEP?, n.d.). When looking at the effectiveness of the KEEP intervention for foster and kin parents, parents "reported significantly fewer child behavior problems" at the termination of the KEEP intervention compared to at baseline (Price, Chamberlain, Landsverk, \& Reid, 2009, p.237). KEEP was also found to be beneficial for increasing positive parenting skills such as increased use of positive reinforcement to help reduce problem behaviors (Price et al., 2009). Price et al. also found that children who participated in the KEEP intervention group were more likely to experience positive exits from foster care (2009). Positive exits refer to reunification with the birth family or adoption (Price et al., 2009). 
Based on the literature, there appears to be a gap in current programming for community members who work with children in foster care. Community members can work with children in foster care in a variety of settings. They can be daycare providers, school staff, extended family members, etc. These individuals could benefit from the knowledge about the foster care system, childhood trauma, and the needs of a foster child. Although there are current programs that utilize the occupation of play, this program will differ as it will utilize the occupation of play to support the development of children in foster care.

\section{Benefits of Play}

Play has numerous benefits for a child as it can support and aid in development while also increasing a child's overall physical activity rate (Roach \& Keats, 2018). Healthy weight, motor skill development, overall mental health and metabolic health are associated with participation in physical activity (Tortella et al., 2019). Play can also help a child mature emotionally and develop the confidence and skills necessary to interact with others and explore a new environment (AOTA, 2012). Some research states that unstructured play is insufficient for developing fundamental movement skills in a child (Roach \& Keats, 2018). While an unstructured free play approach is often more enticing for children, both unstructured and structured play have their advantages (Roach \& Keats, 2018).

\section{Literature Review Conclusion}

In summary, childhood trauma is the underlying cause of many challenges that a foster child experiences. Training programs have started to evolve for foster parents and teachers to help understand the needs of this population. However, this programming does not appear to have evolved for community members. Community members could benefit from additional 
training to support the development of children in foster care through the use of the occupation of play.

\section{Chapter 3: Project Description}

This project focused on the occupation of play to support the development of children in foster care. Play is the number one occupation for children and is essential for a child's overall growth and development. Children in foster care experience a number of challenges due to the trauma and abuse experienced at a young age. These challenges can take a toll on parents of children in foster care which often results in increased rates of caregiver burden. This project aimed to educate community members on the developmental needs of children in foster care, the importance of play, how to utilize play to support child development, and how to utilize play to foster the connection between foster families.

This project took place at an outpatient pediatric clinic, Growing Healthy Children Therapy Services in Rescue, California. The Doctor of Occupational Therapy student (OTD) worked with children in foster care, adopted children, foster families, and families enrolled in the summer camp program. The aim of this portion of the project was to gain additional experience and knowledge on how to use play to support child development and how play is used in occupational therapy practice. Throughout the six-week summer camp program, the OTD student worked with level II occupational therapy students, occupational therapists, and occupational therapy assistants to develop play-based activities for summer camp for children ages four through fifteen. Through this activity, the OTD student was able to learn about proper grading of play activities, potential sensory triggers to activities, and how to support the social connection to meet the individualized needs of children in foster care and adopted children. 
Additionally, in this part of the project, information was gathered through observation and participation in occupational therapy treatment sessions with children who were adopted or who are currently in foster care. Through the observation and participation in occupational therapy treatments, the OTD student was able to gain additional knowledge and experience on play-based activities, how to incorporate developmental skills into play-based activities, and how to use play to foster the connection between children and adults.

In order to learn about the challenges related to occupational performance that children face when exposed to childhood trauma, the OTD student attended webinars and online trainings relating to trauma-informed care and the effects of childhood trauma on children in foster care. Following these trainings, discussions with occupational therapists were used to help brainstorm strategies on how to use play to foster the relationship between therapist and child and parent and child. The information gathered helped guide the program development process.

Following the development of the play-based program for children in foster care and adopted children, a resource was created that can be used by community members who work with adopted children or children in foster care in their profession. This resource could also be used by foster and adoptive families in the home environment. A survey was developed and used to help identify qualitative themes and quantitative data to meet the program objectives six and seven which measure the understanding and receptiveness of community members on the program and the likelihood of implementing the program into their professional services. See Appendix A for a copy of the survey questions for community members. See Appendix B for a copy of the resource, Turning Everyday Activities into Play - Home Guide, which was presented to community members. 
There was a total of four different stakeholders for this program. These groups are occupational therapists, parents of children in foster care or adopted children, community members who work with this population in their profession, and children in foster care or adoptive children. The roles of these participants were discussed in the paragraphs above. All four groups of participants play a key role in the program development and implementation process. While the goal is to create this program for community members, it can be an additional tool that occupational therapists can use in their profession. This program utilized everyday activities and provided participants with strategies on how to turn these activities into play. By doing this, this program can be used in the home environment by foster and adoptive families.

\section{Program Planning Model}

The logic model for this project has the inputs of evidence-based research on the importance of play for children in foster care, observation and research on play-based activities, and connections within the community for those who work with the foster care population. One of the outputs requires the creation of a resource on play and play-based activities. This resource will be intended for community members but can also be beneficial for foster families to educate on the importance of play and how to use play at home to support child development. Educating on the importance of play is another output of the logic model. The third output relies on community connections and developing relationships with the foster community to be able to implement the program.

There are short, medium, and long-term goals associated with the logic model for this program. The short-term goals are on increasing knowledge on play-based activities to support child development and increase knowledge on the importance of play. Creating a resource for community members will help achieve this short-term goal. 
The medium-term goals of this project are community members feeling more competent in supporting the development of a child in foster care and increasing the number of community members who utilize play as a tool to support development. Together these goals help shape the long-term goals. These goals consist of the following: increase in foster placement stability and increase in the number of individuals who can support children in foster care in a variety of settings. See Appendix C for a visual of the logic model discussed above.

\section{Process}

The first portion of the capstone experience focused on expanding the literature review and preparing for the in-person capstone experience. Due to the COVID-19 pandemic, the first few months of the capstone experience (March-May) were spent at home as all California Residents were required to "shelter-in-place" until June. Shelter-in-place required all nonessential businesses to shut down. Some of these businesses included hair and nail salons, retail stores, business offices, and schools.

Due to COVID-19, there were many changes within the community that took place to help stop the spread of the virus. These changes were challenging for everyone but were especially difficult for children who did not completely understand what was going on in the world. Some of these changes that took place were that schools transitioned from an in-person format to an online "distance learning" format. Additionally, child care and day care providers were forced to temporarily close. Many employees who were not deemed essential were required to work from home and care for children in home. Many children lost out on social opportunities due to distance learning, sports seasons being canceled, after-school programs being shut down, and many summer activities being canceled. 
At the beginning of June, essential businesses, such as the Growing Healthy Children Therapy Services were able to open again. At the start of the six week long summer camp program at Growing Healthy Children, many parents reported on the challenges they have been experiencing as a family due to COVID-19. Parents expressed how challenging it has been to shelter-in-place as a family and that summer camp was a great opportunity for children to get back into a routine and to provide children the opportunity to socialize and be around other children again.

After having these conversations with families, the decision was made to shift the focus of the capstone project to include families even more than originally planned. With children learning from home due to distance learning and childcare services being closed, families were spending a lot of time at home together. Families no longer had the physical support provided by teachers, school personnel, respite providers, day care providers, etc. that they did previously. Additionally, with many non-essential businesses being closed and the risk associated with going into public with large crowds, many families reduced the number of public outings that were not necessary.

\section{Program Changes}

The idea for the home guide was developed after considering the challenges families were experiencing due to COVID-19. It was important to include activities in the home guide that could be completed at home with minimal supplies or supplies available around the home. By doing so, families did not have to make unnecessary trips to gather supplies and equipment.

The home guide still focused on the occupation of play. However, the goal was to provide strategies on how to turn everyday household activities into play. It was also essential to 
support child development and foster the connections and relationships of families. The home guide's goal was to be a resource that could be used by both families and community members.

Additionally, another change made was to include adopted children as stakeholders for this program. After working with adopted children in the clinic setting and during the summer camp experience, it was apparent that adopted children often face many of the challenges that children in foster care face. The concepts and activities discussed in this program applied to this population, making it appropriate to include them in the program moving forward.

\section{Timeline}

March, April, May 2020

- Conduct a literature review to learn about gaps in current programming for children in foster care.

- Through literature review, identify the developmental needs related to occupational participation of children in foster care due to the childhood trauma experienced at a young age.

- Brainstorm survey and interview questions

- Prepare for summer camp at Growing Healthy Children Therapy Services

○ Brainstorm play-based activities

- OTAC \& AOTA webinars on foster care, childhood trauma, trauma informed care

- Research on current programming available for foster and adoptive families

- Trauma informed care training course

\begin{tabular}{|c|c|c|}
\hline June 2020 & July 2020 & August 2020 \\
\hline $\begin{array}{l}\text { Begin capstone } \\
\text { experience at Growing } \\
\text { Healthy Children } \\
\text { Therapy Services } \\
(6 / 1 / 2020) \\
\text { - Research and plan play- } \\
\text { based summer camp } \\
\text { activities } \\
\text { - Observe play-based } \\
\text { occupational therapy }\end{array}$ & $\begin{array}{l}\text { Observe play-based } \\
\text { occupational therapy } \\
\text { sessions } \\
\text { Begin leading play- } \\
\text { based activities during } \\
\text { occupational therapy } \\
\text { sessions } \\
\text { - } 3 x \text { weekly sessions with } \\
\text { adopted siblings, using } \\
\text { play-based activities to }\end{array}$ & $\begin{array}{l}\text { Observe play-based } \\
\text { occupational therapy } \\
\text { sessions } \\
\text { - } \quad \text { Lead play-based } \\
\text { activities during } \\
\text { occupational therapy } \\
\text { sessions } \\
\text { Data collection on } \\
\text { surveys from } \\
\text { community members }\end{array}$ \\
\hline
\end{tabular}




\begin{tabular}{|c|c|c|}
\hline 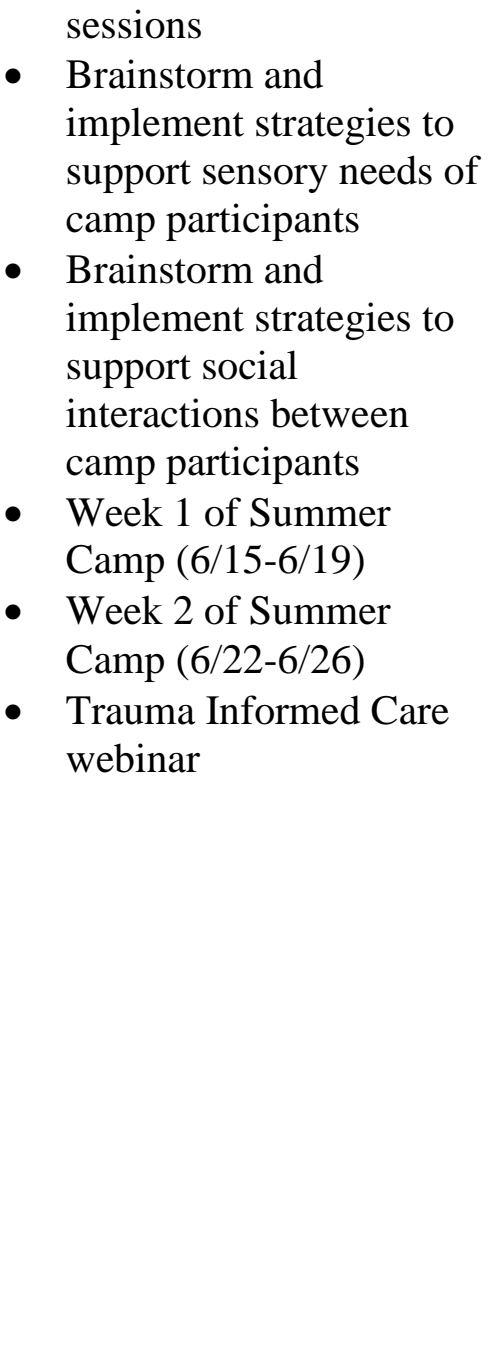 & 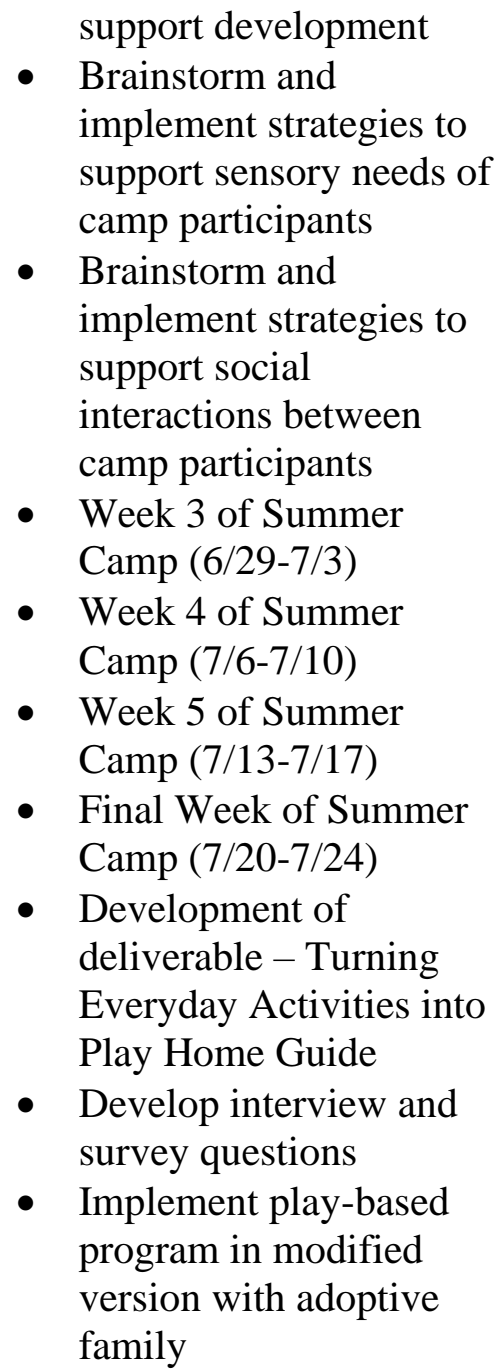 & $\begin{array}{l}\text { - Identify themes from } \\
\text { survey } \\
\text { - } \text { Present deliverable to } \\
\text { Growing Healthy } \\
\text { Children Therapy } \\
\text { Services } \\
\text { - Overall data analysis } \\
\text { looking at success of } \\
\text { program }\end{array}$ \\
\hline
\end{tabular}

\section{Chapter 4: Results \& Analysis}

The home guide for Turning Everyday Activities into Play was created to provide a resource that is easily accessible and that can be used in the home or professional environment. The home guide provides strategies on how to make tasks easier or harder to allow for families to continuously provide the just right challenge for children as their needs and skills change and develop. This program also provides readers with the background knowledge of the needs of children in foster care and adoptive children by explaining the lasting implications of childhood trauma. Not only does this resource use play to work on a child's developmental motor and 
sensory skills, but it also provides strategies to work on communication skills that help foster connections and build relationships. Play can be tailored to best fit the needs of a child and the child's interests to be used as a motivating tool. Play provides children and families the opportunity to work on the skills necessary to establish a sense of trust, security, and comfort to build stronger bonds and relationships.

Data analysis was required as surveys and interviews were both a part of this project. An interview was created for foster and adoptive families with the intention of implementing Turning Everyday Activities into Play as a week-long virtual program. This interview consisted of mostly open-ended questions to provide the OTD student with additional information on the family as well as the family's goal(s) for the program. Unfortunately, there were no participants in either of the week-long virtual programs offered for foster and adoptive families. Moving forward with future implementation of this program, the interview questions will be used to find ways to tailor specific everyday activities to best meet the needs and goals of the family. See Appendix D for the interview questions created for foster and adoptive families.

A six-question survey was developed for the community member participants of this program. The survey consisted of a variety of questions, some being open-ended and some being multiple choice. The survey was sent along with the Turning Everyday Day Activities into Play Home Guide to community members who work with foster and adoptive families in their profession. The survey and home guide were distributed to 40 participants and a total of 26 surveys were returned. The participants consisted of:

- Occupational Therapist (OT), Occupational Therapy Assistant (COTA), OT Student

- Speech-Language Pathologist, SLPA, SLP student

- Physical Therapist (PT), Physical Therapy Assistant, PT student

- Teacher

- Paraeducator

- Special Education Teacher 
- Psychologist

- Inclusion Specialist

- Program Specialist

- Counselor

- Family Therapist

- Social Worker

- School Administrator

- Nurse

- Board Certified Behavior Analyst (BCBA), Applied Behavior Analyst (ABA)

- Daycare/child care provider

- Respite care provider

The three short answer questions required coding for qualitative themes and the three multiple choice questions required data collection and analysis to organize the quantitative data. The first question informed the OTD student in which role the community member worked with foster and adoptive children in the community. Many participants work with this population in multiple professional roles and marked more than one profession in the survey question. The breakdown of the participants can be seen in the Table 1. The top 3 professions of the community member participants were occupational therapists, school psychologists, and special education teachers. 11 of the 26 participants were occupational therapists, occupational therapy assistants, or occupational therapy students. Seven of the 26 were school psychologists. Five of the 26 participants were special education teachers. The other professional roles are listed in Table 1.

Table 1

Professional Roles of Community Member Participants

No. of participants

Occupational Therapist (OT), Certified 11

Occupational Therapy Assistant (COTA), Occupational Therapy Student

School Psychologist 
Special Education Teacher $\quad 5$

Speech Language Pathologist (SLP), Speech 3

Language Pathologist Assistant (SLPA)

Daycare/Childcare Provider 3

Paraeducator 2

Counselor $\quad 2$

Family Therapist 2

Board Certified Behavior Analyst (BCBA) 2

Teacher 1

Program Specialist 1

School Administrator 1

Non-Profit for Foster Youth 1

$\begin{array}{ll}\text { Total no. of participants } & 26\end{array}$

Overall, there was a good variety in the professions of the community members who were program participants. With 26 survey participants, there were 14 different professions represented. This demonstrates how many professionals work with and see foster and adoptive families in their profession that have the opportunity to impact the life of a child in foster care or adopted child. To expand this project, by including more community member participants, it will be an opportunity to include professions that were not represented in the initial program implementation. Other community members that would be beneficial to include in the future would be social workers, youth advocates, respite care providers, ABA therapists, other mental health specialists, and foster agency staff members.

The second survey question asked, what was something that you learned from this resource? The themes that were discovered were on the importance of play, how to connect and engage my students, the importance of understanding sensory triggers, and the needs of children in foster care. The qualitative themes that were discovered confirmed that the goals of this program were met. One of the main goals of this program was to inform participants on the needs of foster children while considering the effects of childhood trauma. Another goal of this 
program was to use the power of play to support regulation and build stronger bonds and relationships.

\section{Table 2}

Survey Question 2 Themes: What was something that you learned from this resource?

\begin{tabular}{|c|c|}
\hline Themes & Examples \\
\hline Importance of Play & $\begin{array}{l}\text { "Play is an important activity for kids" (P4) } \\
\text { "Play is accessible to everyone! Mundane chores and tasks } \\
\text { can be made enjoyable for everyone, I love it!" (P14) } \\
\text { Play can be used to enhance things that we do every day } \\
\text { which is important for a child's overall growth (P18) } \\
\text { Can enhance carry-over skills (P19) }\end{array}$ \\
\hline How to Connect/Engage & $\begin{array}{l}\text { "connecting with students through probing questions in } \\
\text { regards to food and exercise might be a great way to } \\
\text { connect and engage my students" (P2) } \\
\text { "I learned about various ways to increase social } \\
\text { connections with kids and tips I can provide family } \\
\text { members" (P5) } \\
\text { "The "How to foster connection" section included on } \\
\text { many topics is a great resource as often I don't think of } \\
\text { parents or caregivers an how their relationship could be } \\
\text { altered due to past circumstances in the child's life" (P12) }\end{array}$ \\
\hline Effects of Childhood Trauma & $\begin{array}{l}\text { Although an activity is seemingly fun, there can be } \\
\text { potential sensory triggers for students who have } \\
\text { experienced trauma (P1; P3; P22) } \\
\text { Potential triggers can affect a child's learning and } \\
\text { development (P1) } \\
\text { How self-regulation affects foster and adopted children. "I } \\
\text { was able to connect some of the self-regulation activities to } \\
\text { some of my students at work who have been exposed } \\
\text { through childhood trauma" (P7) } \\
\text { Sensory triggers may seem so small to me but they can be } \\
\text { incredibly distracting for my students (P15) }\end{array}$ \\
\hline
\end{tabular}


Children who are in foster care or who have been adopted can have a hard time letting others in due to their traumatic experiences. This resource teaches different ways to build that relationship (P26)

The third question asked, in your opinion, what was the most valuable information or topic that was presented in this resource? The themes that were discovered were the glossary to allow a better understanding of commonly used terms, how to tailor activities to best fit a child's needs, and how to use play to support development, connections, and relationships.

\section{Table 3}

Survey Question 3 Themes: In your opinion, what was the most valuable information or topic that was presented in this resource?

\begin{tabular}{ll}
\hline Themes & Examples \\
\hline How to use Play to & The use of everyday activities is a way for families to connect in \\
Support Development, & ways they might not have thought (P2; P24) \\
Connection, and & "How play is such an important area in which parents and \\
Relationships & caregivers can help kids to grow and develop their skills" (P5) \\
& "I think the specific strategies you provided in each section on \\
& how to specifically foster and increase connection" (P11) \\
& "How to foster connection and increase social connection. These \\
& are so important to emphasize to parents/caregivers" (P17) \\
"I really liked the activity ideas to work on their skills. Especially & the upgrades and downgrades" (P7) \\
"The specific ways to grade the activities to make them harder & or easier. This is something families have a hard time knowing \\
how to Tailor Activities do. This really allows an activity to be a positive & experience for the child" (P9) \\
& Connecting the triggers and the strategies to incorporate \\
& solutions with play (P13; P26) \\
Breaking things down to easy, medium, difficult, how to & "upgrade" or "downgrade" (P18; P25)
\end{tabular}


Commonly Used Terms The glossary which allows parents to understand the terms as they relate to the activities (P4; P6)

New terms to me such as: Bilateral integration, crossing midline, proprioception (P8; P23)

The terms and definitions were helpful and made it easier to understand concepts in the program (P26)

The fourth question asked, moving forward, how would you use this resource in your profession? The results can be seen in the Table 4. The majority of responses from community members state that this home guide can be used as a resource or home program. The second highest response was that community members would use this resource in their profession by applying the concepts discussed in the home program. Two participants selected the other option and explained that they can use this resource with children of different backgrounds and diagnoses.

\section{Table 4}

Survey Question 4: Moving forward, how would you use this resource in your profession? (Mark all that apply)

\begin{tabular}{lc}
\hline & No. of responses \\
\hline $\begin{array}{l}\text { Provide it as a resource or a home program } \\
\text { for a child }\end{array}$ & 21 \\
$\begin{array}{l}\text { Apply the concepts discussed in the resource } \\
\text { to my profession }\end{array}$ & 19 \\
Use specific activities discussed in the & 17 \\
resource & 2 \\
Other & \\
\hline
\end{tabular}

The fifth question asked, who would you recommend this resource to? The results are shown in the Table 5. The top two responses were to recommend this resource to other professionals and to all families that a community member works with in their profession. 


\section{Table 5}

Survey Question 5: Who would you recommend this resource to? (Mark all that apply)

\begin{tabular}{lc}
\hline & No. of responses \\
\hline Other Professionals & 22 \\
All Families That I Work With & 22 \\
Foster or Adoptive Families & 17 \\
Other & 2 \\
\hline
\end{tabular}

The last question asked participants how the resource can be improved and what topics/information should have been discussed. As this was a short answer question, some of the discovered themes were: needing specific step-by-step instructions of activities or recipes, adding information on other routines - night time or community routines, and how to include siblings and foster the sibling relationship. The home guide and survey were distributed to community member participants in August 2020. Since then, the home guide has been modified based on the feedback received in question six. There have been slight modifications to some activities discussed and sections added on emotions and how to include siblings in play.

\section{Table 6}

Survey Question 6 Themes: How can this resource be improved or what topics/information should have been discussed?

\begin{tabular}{ll}
\hline Themes & Examples \\
\hline Expanding the Resource & Add testimonials from families that have tried these \\
activities and how it has helped them (P22) & Family outings (P16; P19) \\
Component on communication and talking to the child \\
through each section (P17) \\
Including a section on education. Parents may need more \\
support with more homeschooling and virtual learning in \\
today's world (P12)
\end{tabular}




$\begin{array}{ll}\text { Provide Step-by-Step } & \begin{array}{l}\text { Provide strategies to work on specific skills such as fine } \\ \text { motor, obstacle course breakdowns to provide movement } \\ \text { Instructions }\end{array} \\ \text { Links or videos to provide instructions for games or } \\ \text { activities mentioned (P3; P8; P9; P10) } \\ \text { Opportunities to share personal emotions to normalize the } \\ \text { experience (P20) } \\ \text { Fostering the relationship with siblings and other foster } \\ \text { kids (P5) }\end{array}$

After reviewing and analyzing the data from the survey responses, it was apparent that this program can be used in a wide variety of professions that work with children in foster care and children who were adopted. From the survey responses it was interesting to see that the participants were finding ways to connect the concepts discussed in this program to other students and children that have not been in foster care or adopted. It is important to note that a child can experience childhood trauma without being in foster care or adopted. Through this data, it showed that this program can be expanded to include children of other backgrounds and children with other diagnoses as they too can benefit from the use of play to support development and to help strengthen relationships.

\section{Chapter 5: Discussion and Conclusion}

\section{Discussion}

The purpose of this capstone project was to create a program for community members, foster families, and adoptive families. The goal of this program is to use play to build stronger family bonds and relationships while also supporting the development of children in foster care and adopted children. By providing this program as a tool that can be used by families and community members, this can help bridge the gap and inconsistencies with current trainings and programming. 
The development and implementation of Turning Everyday Activities into Play affirmed that play can be a powerful tool especially when working with foster and adoptive children. This program also showed that although an individual might work with foster and adoptive children in their profession, it is always important to consider the effects of childhood trauma and use a motivating tool such as play to support development and build connections. This project also showed that educating and providing community members with this resource is a great way to indirectly make a difference in the lives of foster and adoptive families.

Although it would have informative to implement this program with foster and adoptive families directly, it provides a goal for envisioned next steps of this project. While also considering the feedback provided by community members, there are many ways to continue to expand and improve the program.

Turning Everyday Activities into Play is a program that can be used as a tool to help educate foster parents, adoptive parents, and community members who work with this population in their profession. Including community members in this program will help with the sustainability of this program as these individuals can continue to share this program and their knowledge gained from this program with other families and professionals.

\section{Implications for OT}

Although OTs working in pediatrics and school-based settings incorporate the occupation of play into treatment sessions daily, this program can be a useful tool for OTs who work with foster and adoptive families. This program can educate therapists on the effects of childhood trauma and what it may look like when working with children in foster care or who were adopted. OTs can use the activities or concepts discussed in this program to build rapport and 
strengthen their connection with a child. This program can serve as another tool in the OT toolbox to support child development, connections, and relationships.

Additionally, there are a couple different ways that OTs can use this program. First, OTs can use this program as a way to include parents in treatment sessions. Therapists can go over specific concepts or activities discussed in this program to include parents in the session by showing how easy it is to make everyday activities therapeutic and playful. Therapists can also provide this resource to parents as a home program to work on developmental skills and communication skills at home to strengthen the family relationships. Although this program is directed at foster and adoptive children, the concepts and activities can be used with children of other diagnoses and abilities.

This program utilizes everyday activities that are done in the home such as cooking, playing, and household chores. The goal of using these activities that take place around the home, was to ensure that this program was appropriate for all families. By providing strategies on how to foster the connection, how to increase social connection, and how to modify the activity to increase or decrease the challenge, families are able to apply those strategies to their own routines at home.

Lastly, it is important to remember that as an occupational therapist, specifically a pediatric occupational therapist, play is used constantly to support child development and is incorporated into tasks to help work towards a child's established goals. Other factors such as social interactions, functional communication, and a child's relationship with peers and family are all areas that occupational therapists focus on each day in practice. Through this program, it showed how beneficial it is to empower other professionals to utilize occupations and make seemingly simple activities enjoyable and therapeutic to best serve the child and family. 


\section{Conclusion}

While many occupational therapists are trained on providing trauma-informed care and use play as a tool to help children work through the effects of trauma, other professionals may not have the knowledge or training to do so. By using an occupational therapy lens, this program was able to educate and empower community members on how to do the things that OTs do every day in practice. By empowering others to utilize the power of play while also considering the effects of trauma, OTs, community members, and parents can work together to mitigate the effects of childhood trauma for children and foster care and adopted children. 


\section{References}

American Occupational Therapy Association. (2012). Play.

https://www.aota.org/about-occupational-therapy/patients-

clients/childrenandyouth/play.aspx

American Occupational Therapy Association. (2015). Childhood trauma [PDF file].

https://www.aota.org/ /media/Corporate/Files/Practice/Children/Childhood-Trauma-

Info-Sheet-2015.pdf

American Occupational Therapy Association. (2016). Occupational therapy in school settings.

https://www.aota.org/About-Occupational-Therapy/Professionals/CY/schoolsettings.aspx

American Occupational Therapy Association. (2017). Foster care [PDF file].

https://www.aota.org/ /media/Corporate/Files/Practice/Children/SchoolMHToolkit/Foste r-Care-Info-Sheet-20170320.pd

American Occupational Therapy Association. (2020). Medicaid.

https://www.aota.org/Advocacy-Policy/Federal-Reg-Affairs/Pay/medicaid.aspx

Bazyk, S. (2014). Every moment counts information brief [PDF file].

https://everymomentcounts.org/view.php?nav_id=2

Child Welfare Information Gateway. (2015). Health-care coverage for youth in foster care and after [PDF file]. https://www.childwelfare.gov/pubPDFs/health_care_foster.pdf

Child Welfare Information Gateway. (n.d.) State resources. https://www.childwelfare.gov/

Cox, T. L. (2013). Improving educational outcomes for children and youths in foster care.

Children \& Schools, 35(1), 59-62. https://doi.org/10.1093/cs/cds040

Dudgeon, B. J., \& Greenberg, S. L. (1998). Preparing students for consultation roles and 
systems [PDF file]. American Journal of Occupational Therapy, 52(10), 801-809. https://doi.org/10.5014/ajot.52.10.801

Farias, C. de A., Cardoso, T. de A., Mondin, T. C., Souza, L. D. de M., da Silva, R. A., Kapczinski, F., ... Jansen, K. (2019). Clinical outcomes and childhood trauma in bipolar disorder: A community sample of young adults. Psychiatry Research, 275, 228-232. https://doi.org/10.1016/j.psychres.2018.12.114

Greeno, E., Lee, B., Uretsky, M., Moore, J., Barth, R., \& Shaw, T. (2016). Effects of a foster parent training intervention on child behavior, caregiver stress, and parenting style. Journal of Child \& Family Studies, 25(6), 1991-2000. https://doi.org/10.1007/s10826015-0357-6

Hebert, C. G., \& Kulkin H. (2018). An investigation of foster parent training needs. Child \& Family Social Work, 23(2), 256-263. https://doi.org/10.1111/cfs.12413

Howard, A. R., Parris, S. R., Nielsen, L. E., Lusk, R., Bush, K., Purvis, K. B., \& Cross, D. R. (2014). Trust-Based Relational Intervention ${ }^{\circledR}$ (TBRI®) for adopted children receiving therapy in an outpatient setting. Child Welfare, 93(5), 47-64.

Kielhofner, G. (2008). Model of human occupation: Theory and application. (4th ed.). Lippincott Williams \& Wilkins.

La Corte, L. F. (2008). New and expanded concepts in neurophysiology, psychology, and sociology complementary to Llorens' developmental theory: Achieving growth and development through occupation for neonatal infants and their families. Occupational Therapy in Mental Health, 24(3/4), 201-349. https://doi.org/10.1080/01642120802257764

Lee, S. W., Kielhofner, G., Morley, M., Heasman, D., Garnham, M., Willis, S., ... Taylor, R. R. 
(2012). Impact of using the Model of Human Occupation: A survey of occupational therapy mental health practitioners' perceptions. Scandinavian Journal of Occupational Therapy, 19(5), 450-456. https://doi.org/10.3109/11038128.2011.645553

Lickteig, S. J., \& Lickteig, A. (2019). Forgotten and overlooked: A personal reflection of foster parenting and school. Educational Considerations, 44(2). http://search.ebscohost.com/login.aspx?direct=true\&db=eric\&AN=EJ1206237\&site=edslive

Liu, C., Chen, X., Song, P., Lu, A., Wang, L., Zhang, X., \& Huang, Z. (2018). Relationship between childhood emotional abuse and self-esteem: A dual mediation model of attachment. Social Behavior \& Personality: An International Journal, 46(5), 793-800. https://doi.org/10.2224/sbp.6655

Lynch, A., Ashcraft, R., Paul-Ward, A., Tekell, L., Salamat, A., \& Schefkind, S. (2017). Occupational therapy's role in the foster care system [PDF file]. https://www.aota.org/ /media/Corporate/Files/Practice/Children/SchoolMHToolkit/Foste r-Care-Info-Sheet-20170320.pdf

Miller, A. E., Green, T. D., \& Lambros, K. M. (2019). Foster parent self-care: A conceptual model. Children and Youth Services Review, 99, 107-114. https://doi-org.prxusa.lirn.net/10.1016/j.childyouth.2019.01.014

Parham, L. D., \& Fazio, L. (2008). Play in occupational therapy for children (2nd ed.) St. Louis, MO: Elsevier.

Price, J. M., Roesch, S. C., \& Walsh, N. E. (2012). Effectiveness of the KEEP foster parent intervention during an implementation trial. Children and Youth Services Review, 34(12), 2487-2494. https://doi.org/10.1016/j.childyouth.2012.09.010 
Roach, L., \& Keats, M. (2018). Skill-based and planned active play versus free-play effects on fundamental movement skills in preschoolers. Perceptual \& Motor Skills, 125(4), 651668. http://prx-

usa.lirn.net/login?url=http://search.ebscohost.com/login.aspx?direct=true $\& d b=s 3 h \& A N=$ $130814022 \&$ site $=$ eds-live

Robison, M., Lindaman, S. L., Clemmons, M. P., Doyle-Buckwalter, K., \& Ryan, M. (2009). "I deserve a family": The evolution of an adolescent's behavior and beliefs about himself and others when treated with Theraplay in residential care. Child \& Adolescent Social Work Journal, 26(4), 291-306. https://doi.org/10.1007/s10560-009-0177-x

Shea, C.-K., \& Siu, A. M. H. (2016). Engagement in play activities as a means for youth in detention to acquire life skills. Occupational Therapy International, 23(3), 276-286. https://doi-org.prx-usa.lirn.net/10.1002/oti.1432

Tortella, P., Haga, Ingebrigtsen, J. E., Fumagalli, G. F., \& Sigmundsson, H. (2019). Comparing free play and partly structured play in 4-5-years-old children in an outdoor playground. Frontiers in Public Health. https://doi.org/10.3389/fpubh.2019.00197

U.S. Department of Health and Human Services. (2018). The AFCARS report. https://www.acf.hhs.gov/sites/default/files/cb/afcarsreport26.pdf

What is KEEP? (n.d.). https://www.keepfostering.org 


\section{Appendix A - Survey Questions for Community Members on Home Guide}

\begin{tabular}{|c|}
\hline Survey Question \\
\hline $\begin{array}{l}\text { In which role do you work with or could work with foster or adopted children? (Mark all that } \\
\text { apply). } \\
\text { *check boxes } \\
\text { - Occupational Therapist (OT), Occupational Therapy Assistant (COTA), OT Student } \\
\text { - Speech-Language Pathologist, SLPA, SLP student } \\
\text { - Physical Therapist (PT), Physical Therapy Assistant, PT student } \\
\text { - Teacher } \\
\text { - Paraeducator } \\
\text { - Special Education Teacher } \\
\text { - Psychologist } \\
\text { - Inclusion Specialist } \\
\text { - Program Specialist } \\
\text { - Counselor } \\
\text { - Family Therapist } \\
\text { - Social Worker } \\
\text { - School Administrator } \\
\text { - Nurse } \\
\text { - Board Certified Behavior Analyst (BCBA), Applied Behavior Analyst (ABA) } \\
\text { - Daycare/child care provider } \\
\text { - Respite care provider }\end{array}$ \\
\hline What was something that you learned from this resource? *short answer \\
\hline $\begin{array}{l}\text { In your opinion, what was the most valuable information or topic that was presented in this } \\
\text { resource? *short answer }\end{array}$ \\
\hline $\begin{array}{l}\text { Moving forward, how would you use this resource in your profession? }{ }^{*} \text { check boxes } \\
\text { - Provide it as a resource or a home program for a child } \\
\text { - Use specific activities discussed in the resource } \\
\text { - Apply the concepts discussed in the resource to my profession }\end{array}$ \\
\hline $\begin{array}{l}\text { Who would you recommend this resource to? } * \text { check boxes } \\
\text { - Other professionals who work with foster and adoptive families in the community } \\
\text { - Foster or adoptive families } \\
\text { - All families that I work with in my profession }\end{array}$ \\
\hline $\begin{array}{l}\text { How can this resource be improved or what topics/information should have been discussed? } \\
\text { *short answer }\end{array}$ \\
\hline
\end{tabular}


Appendix B - Turning Everyday Activities into Play - Home Guide

\section{TURNING EVERYDAY ACTIVITIES INTO}
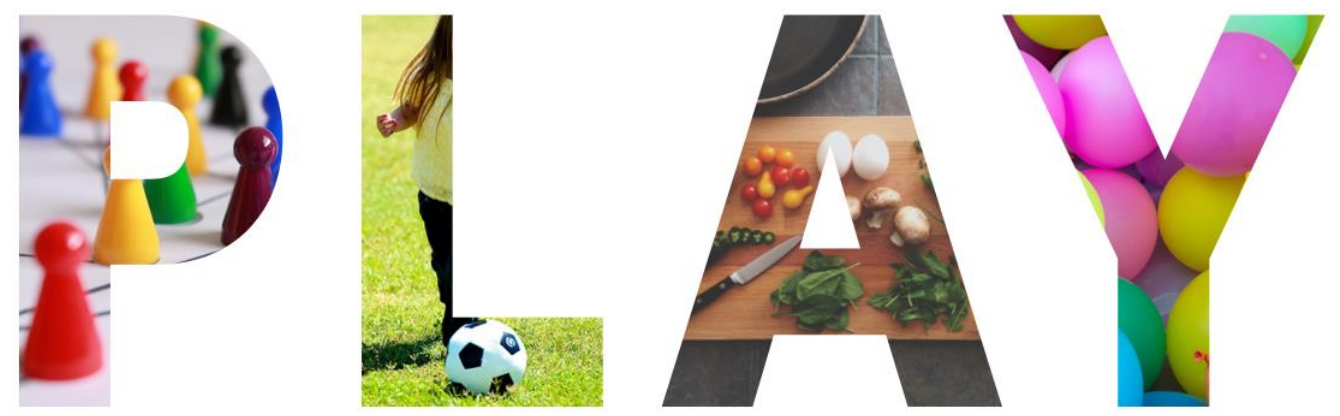

Supporting regulation. Fostering connections. Building relationships.

A capstone project by Marissa Siu, Doctor of Occupational Therapy Student

University of St. Augustine for Health Sciences | September 2020 


\section{CONTENTS}

\begin{tabular}{|c|}
\hline 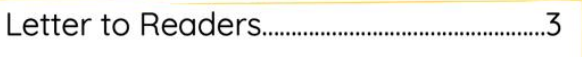 \\
\hline About the Program \\
\hline Terms.............................................................. \\
\hline What is Self-Regulation? \\
\hline Cooking...................................................................7 \\
\hline Exercise................................. \\
\hline 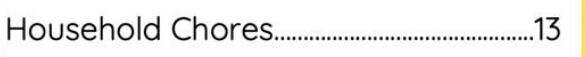 \\
\hline 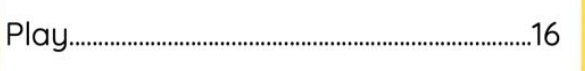 \\
\hline 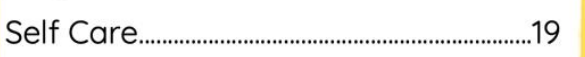 \\
\hline Including Siblings................................ \\
\hline Emotions.................................. \\
\hline 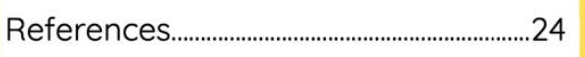 \\
\hline
\end{tabular}

\section{LETTER TO READERS}

\section{Dear Readers:}

My name is Marissa Siu, and I created the program Turning Everyday Activities into Play as a resource for foster families, adoptive families, and those individuals who work with this population in the community. This program was created as a part of my capstone project to fulfill my occupational therapy degree requirements. When creating this program, my goal was to create a resource that can be used at home while incorporating household items and activities. The purpose of this program is to foster the family connection by engaging in fun and enjoyable activities while also allowing all family members to be involved. I hope you enjoy this resource and can utilize it at home or in your profession!

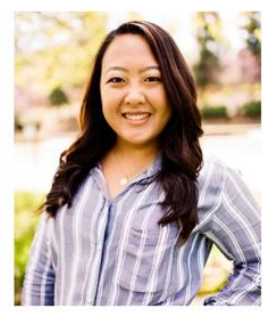

\section{ABOUT THE PROGRAM}

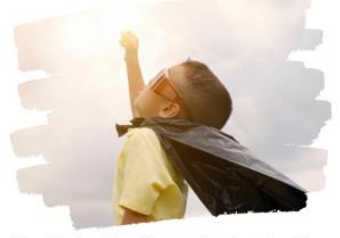

This program is designed for foster families, adoptive families, and individuals who work with this population in the community. Many foster and adopted children experience some form of childhood trauma. Childhood trauma has been linked to poor interpersonal relationships, poor coping strategies, and an increased likelihood to suffer from mental health problems (Liv et al., 2018). Additionally, research has shown that childhood trauma can result in children having difficulty handling their emotions, sensations, and stress (American Occupational Therapy Association, 2015). Children who are placed in foster care need additional support to gain a sense of trust, security. and comfort to allow them to be successful in their new environment (Malek, 2011).

In this program, we will be fostering the connection through everyday activities. We will be using the power of play to support regulation and build stronger bonds and relationships by turning everyday activities into play. The everyday activities discussed in this program are cooking, exercise, household chores/gardening, play, and selfcare.

While this program was designed with children ages 4-15 in mind, the concepts discussed can be used for children outside of this age range and with other diagnoses.

Each activity discussed will provide the following information:

- Activity ideas (easy, medium, hard)

- Skills being targeted

- How to make the activity easier or harder (downgrade or upgrade)

- How to increase the social connection

- How to foster the connection

\section{TERMS}

Bilateral Integration: The use of both sides of the body.

Crossing Midline: Crossing over from one side of the body to the other.

Downgrade: Strategies to make an activity easier.

Fine Motor: Skill requiring the use of the smaller hand muscles - using a pencil, pulling a zipper, buttoning a shirt (Kid Sense, 2020).

Foster the Connection: Ways to strengthen the bond and relationship between adult and child. Gross Motor: Physical skills that require whole body movements inolving the large muscles of the body (Kid Sense, 2020).

Heavy Work: Activities that provide a push or pull against the body.

Insignificant Stimuli: When referring to self-regulation, insignificant stimuli can be sensory input that is not required to complete the task at hand (i.e. the noise of a classmate talking is the insignificant stimuli that needs to be filtered out in order to focus on the teacher presenting). Play: Activities in which children engage.

Proprioception: Involving the muscles and joints of the body. Sense of self and movement (Middletown Centre for Autism, 2020).

Self Care: Activities oriented toward taking care of one's own body (i.e. bathing, toileting, dressing, personal hygiene and grooming)

Self-Regulation: A child's ability to control their feelings, emotions, and behaviors while taking in other internal or external input.

Sensory Trigger: Sensory input that is overwhelming for a child.

Social Connection: Ways to strengthen communication skills or initiate conversations between adult and child.

Tactile Input: Sense of touch, providing different textures and sensations to the receptors of the body and skin (Middletown Centre for Autism, 2020).

Upgrade: Strategies to make an activity more challenging.

Visual Input: Visual information and input provided by light, color, movements, and the environment (Middletown Centre for Autism, 2020).

Vestibular Input: The vestibular system is the movement system. Activities provide speed, direction of movement, and pull of gravity (Middletown Centre for Autism, 2020). 


\section{WHAT IS SELF-REGULATION?}

Self-regulation is the child's ability to control their feelings, emotions, and behaviors while taking in sensory input provided by their body and environment. Self-regulation requires a child to filter out insignificant stimuli and control internal impulses to engage and persist in a task (Paris \& Murray-Slutsky, n.d.; Profectum, 2018). Often, children need to engage in activities to support regulation before working on higher-level skills.

- Some children may require co-regulation, which refers to the use of a parent or adult to help engage in activities to support regulation. Below you'll find some ideas of activities that can help support regulation.

\section{Deep Breathing}

- Blow bubbles

- Blow pom poms along a line

- Tape a line on a table or floor (the floor provides proprioceptive input by requiring your child to lie on their stomach). Place the pom-pom on one end and, with or without a straw, move the pom-pom along the line.

\section{Vestibular input \\ *Disclaimer: Some children are very sensitive to vestibular input. Provide with caution and sma \\ - Going down a slide - Twirling \\ - Dancing \\ - Running \\ - Swinging \\ - Spinning}

\section{proprioceptive input}

- Heavy Work

Carrying a filled laundry basket from the laundry room to a different room. - Put a weighted blanket across your shoulders while completing other activities.

- Obstacle Course

Use household items (couch cushions, pillows, broomsticks, blankets, furniture, balls \& toys, etc.) to create a course that includes various sensory input.

\section{- Animal Walks}

- Choose your favorite animal and try to walk like them across the living room (bear crawl, hop like a frog, crab walks, waddle like a penguin).

\section{COOKING}

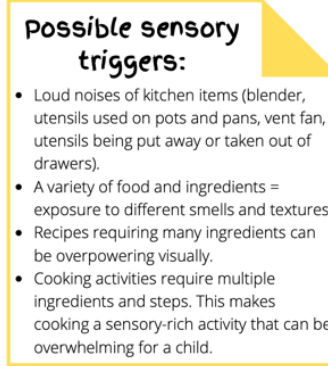

\section{How to foster the} connection:

- Family members can work together to

prepare a meal collectively.

- As a family, create a meal plan for the day or for the week, allowing everyone to enjoy their favorite meals

- Find small ways to include your child in the meal preparation

- Allowing your child to whisk the eggs while you get the pan ready.

- Providing supervision or hand over hand assistance so that your child can help cut

the vegetables.

- Have your child go on a scavenger hunt in the pantry to find the ingredients needed to cook

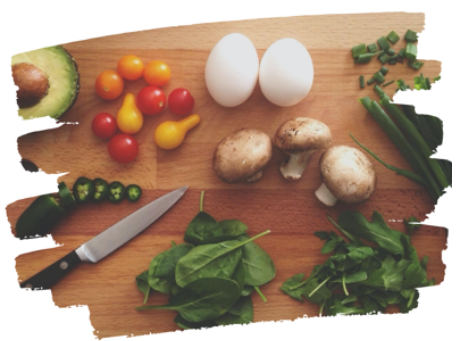

How to increase social connection:

- Askyour child what their favorite food is? - When your child is interacting with the different textures when cooking, ask them questions.

- Is it slimy, or is it soft? - What does it smell like?

- I wonder what we're making!

When creating the family meal plan, take turns sharing ideas for the meals.

- When cooking, play a guessing game and ask your child if they can guess what you're cooking based on the ingredients.

- If your child prepares a meal or snack, ask them how they made it and what ingredients they used.

\section{COOKING}

\begin{tabular}{|c|c|}
\hline \multicolumn{2}{|c|}{$\begin{array}{l}\text { Easy: recipes with minimal ingredients and steps. } \\
\text { - Making pancakes } \\
\text { - Spreading jam, peanut butter, or cream cheese on a bagel or piece of toast } \\
\text { Medium: recipes thes with few ingredients (peanut butter \& jelly, meat \& cheese, etc.) } \\
\text { - Trail mix } \\
\text { - Rice Krispies Treats } \\
\text { - Fruit and granola parfait } \\
\text { Hard: recipes that require preparation (defrosting certain foods, preheating the oven etc.) or planning, } \\
\text { multiple ingredients, steps, textures, sequencing, or the use of tools. } \\
\text { - Cookies } \\
\text { - Vegetable skewers } \\
\text { - Smoothies }\end{array}$} \\
\hline $\begin{array}{l}\text { skills being } \\
\text { targeted: }\end{array}$ & $\begin{array}{l}\text { Upgrades \& } \\
\text { downgrades: }\end{array}$ \\
\hline $\begin{array}{l}\text { - Sequencing: following a recipe or thinking of } \\
\text { the order of the steps to complete a cooking } \\
\text { task. } \\
\text { - Fine motor skills: using your fingers to } \\
\text { open up packaging, using your fingers to pick } \\
\text { up small items (chocolate chips, pieces of } \\
\text { fruit, granola, etc.). } \\
\text { - Exposure to tactile input: using foods that } \\
\text { have different textures, combining different } \\
\text { textures, using your hands to interact with } \\
\text { different textures. } \\
\text { - Grasp: appropriate grasp to hold onto } \\
\text { different kitchen utensills. } \\
\text { - Following multiple step directions: using } \\
\text { a recipe to follow either verbal or written } \\
\text { directions of multiple steps. }\end{array}$ & $\begin{array}{l}\text { - Upgrades: } \\
\text { ○ See if your child can recreate a dish by } \\
\text { following a picture. } \\
\text { - Verbally tell your child which ingredients } \\
\text { are needed and see how many they can } \\
\text { remember. } \\
\text { - With your child, make a list of ingredients } \\
\text { needed for the cooking activity, purchase } \\
\text { the groceries together, return home, and } \\
\text { start cooking! } \\
\text { - Downgrades: } \\
\text { ○ Provide hand over hand assistance with } \\
\text { cutting or scooping. } \\
\text { - Take turns! Switch off with your child and } \\
\text { help break more difficult tasks into } \\
\text { smaller, easier parts. }\end{array}$ \\
\hline
\end{tabular}

\section{Notes}




\section{EXERCISE}

Possible sensory
triggers:
- Activities done outside can provide
unexpected or loud noises.
- Activities done outside can provide
excess visual input and can be
overwhelming for a child.
- Games and movement rich activities can
get noisy and can make it difficult for a
child to calm their body.
- Outdoor activities can provide a variety
of tactile input (grass, dirt, sand, bark,
water, etc.).

\section{How to foster} the connection:

- Exercise is a great opportunity to do activities as a family!

- Going on a family walk or hike around the neighborhood.

- Going on a bike ride as a family.

- Playing an organized game as a team

- As a family, set up a daily exercise routine that includes all members.

- Allow each family member to share ideas on what exercises can be done as a family. As a group decide which ones to do each day. - Grade exercise activities up or down to allow participation from all family members.

- This can be a great opportunity to have fun and explore an activity or place that is new as a family.

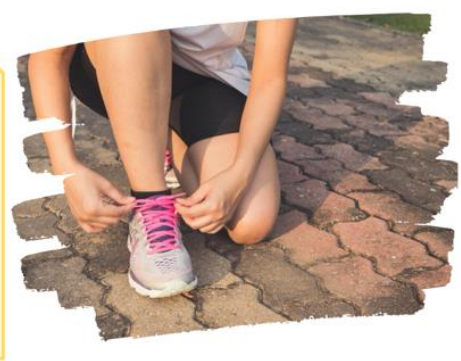

How to increase social connection:

- Ask your child where they want to walk, ride their bike, or hike.

- Make suggestions and provide options if your child has a hard time coming up with ideas on their own.

- Askyour child if there is a game they want to teach to the rest of the family.

If your child needs help with this, you can create a game together.

- As a family, take turns sharing what your

favorite exercise activities are.

- At the end of each exercise activity, take turns

sharing your favorite part of the activity.

- If there is an activity that your child enjoyed, ask if you should do it again or how you can make it better in the future.

\section{EXERCISE}

Activity IdeaS
Easy: simple activities that can be done at a slower pace that are easy to follow along.
- Walk the dog around the neighborhood
- Jump on the trampoline
Medretching activities that require more sensory input, more movement, or that require back and forth
communication with another individual.
- Playing catch outside
Yoga
- Dancing and moving to music
Hard: more complex activities such as organized sports that require more movements and steps.
- Playing a game in the swimming pool (Sharks and Minnows, Marco Polo, Colors)
- Following a dance video game or YouTube dance video
- Team sports or racquet sports

\section{skills being} targeted:

- Sequencing: following directions to a game, what steps need to be completed to go outside to exercise, etc.

- Gross motor skills: exercise is full of different ways to move your body. These are the physical skills necessary for everyday activities. Walking, running, jumping, climbin throwing, catching, core stability, etc. are all. gross motor skills that can be incorporated into exercise activities

- Eye-hand coordination: activities such as throwing, catching, and kicking all work on the coordination between eye and hand movements.

- Bilateral integration: activities that require your child to use both sides of their body together

\begin{tabular}{|c|c|}
\hline & $\begin{array}{l}\text { Upgrades \& } \\
\text { downgrades: }\end{array}$ \\
\hline $\begin{array}{c}\text { - Up } \\
\circ \\
\circ \\
0 \\
\text { - Dov } \\
\circ \\
\circ \\
0\end{array}$ & $\begin{array}{l}\text { grades: } \\
\text { Have your child come up with their own } \\
\text { game and teach it to to the family. } \\
\text { Have your child create a week-long } \\
\text { workout schedule or a homemade } \\
\text { workout to follow. } \\
\text { Add additional steps to a game or } \\
\text { workout circuit. } \\
\text { wngrades: } \\
\text { Provide hand over hand assistance. } \\
\text { Break larger activities into smaller pieces. } \\
\text { Practice the smaller pieces until that step } \\
\text { is mastered and then introduce the next } \\
\text { step. } \\
\text { Demonstrate the activity for your child } \\
\text { before trying it together. }\end{array}$ \\
\hline
\end{tabular}

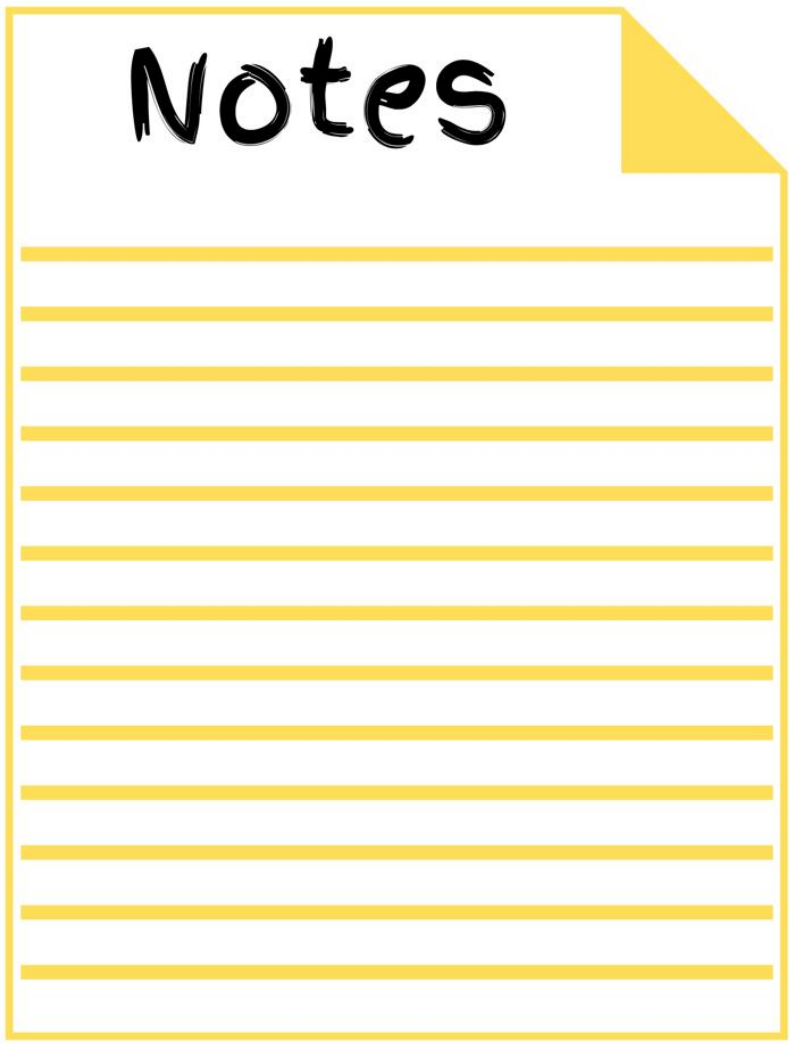

\section{HOUSEHOLD CHORES}

\section{possible sensory triggers: \\ - Loud noise \\ Dishwasher, washer/dryer, vacuum, lawn mower, leaf blower, weed wackers, electric trimmers, etc \\ - Exposure to various tactile input Garden soil, water, clothing textures, laundry detergent, carpet, hard floors, etc. \\ - Strong odors \\ - Trash, household cleaners, animal feces, etc}

- Insects or critters in the garden or home

\section{How to foster the connection:}

- Allow children to make choices.

- Which chores should we do first?

- What chores should we do today?

What vegetables do you want to plant in What vegetables

our garden?

Who should put away which dishes? What activity should we do as a family as a reward for completing our chores? - Do activities as a family. Start by making plan as a family.

Make activities fun and enjoyable by turning activities into a game

Complete smalier tasks that help create bigger project (start a family garden gathering and raking soil, digging holes for the seeds, placing the seeds, watering th garden

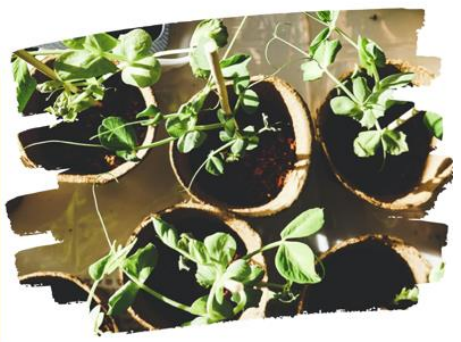

How to increase social connection:

- Allow all family members to voice their opinion and to share their ideas with the group.

- Ask questions.

- How does the garden soil feel? - Can you show me how to do this? I need help carrying the trash outside, can you use your strong muscles and help me? - Ask children if they have any ideas on how to make chores fun.

- Should we pretend our dirty laundry is a basketball and shoot it into the washing machine?

I wonder if it would be fun to use the laundry basket as a car. Maybe you can sit in the basket, and I can pull you down the 


\section{HOUSEHOLD CHORES}

\begin{tabular}{|c|c|}
\hline \multicolumn{2}{|c|}{$\begin{array}{l}\text { Easy: activities that require minimal steps and tools. } \\
\text { - Raking dirt in the garden } \\
\text { - Water the plants in the house or garden } \\
\text { - Wiping the table after dinner } \\
\text { Medium: activities requiring the use of tools, more steps, some sensory input. } \\
\text { - Harvesting the garden } \\
\text { - Vacuuming or mopping the house } \\
\text { - Setting up the table for dinnertime } \\
\text { Hard: activities that require sequencing, waiting time, various sensory input (visual input, textures, } \\
\text { smells, etc.), multiple steps, use of tools (appliances, cleaning supplies, etc.). } \\
\text { - Doing laundry (gathering dirty laundry, washing, drying, folding, and putting away laundry) } \\
\text { - Washing the dishes (gathering dirty dishes, washing, drying, and putting away) } \\
\text { - Grocery shopping (creating a shopping list, searching for groceries, putting them away) }\end{array}$} \\
\hline $\begin{array}{l}\text { skills being } \\
\text { targeted: }\end{array}$ & $\begin{array}{l}\text { Upgrades \& } \\
\text { downgrades: }\end{array}$ \\
\hline $\begin{array}{l}\text { - Sequencing: completing a task with multiple } \\
\text { steps. } \\
\text { - Gross motor skills: an opportunity for } \\
\text { lifting, carrying, pushing, pulling. These are } \\
\text { the physical skills necessary for everyday } \\
\text { activities. } \\
\text { - Fine motor skills: using your fingers for } \\
\text { tasks. These skills can be seen when using } \\
\text { your fingers to dig a hole and plant a seed, to } \\
\text { open a container of laundry or dishwashing } \\
\text { detergent. } \\
\text { - Exposure to tactile input: more } \\
\text { challenging household chores incorporate a } \\
\text { variety of textures such as water, soap, } \\
\text { detergent, soil, seeds, etc. } \\
\text { - Opportunity for heavy work: carrying } \\
\text { objects, pushing/pulling launndry basket or } \\
\text { vacuum, unloading/loading the washer and } \\
\text { dryer. }\end{array}$ & $\begin{array}{l}\text { - Upgrades: } \\
\text { - Have your child brainstorm the steps } \\
\text { necessary to complete the household } \\
\text { chore before completing the task. } \\
\text { - Have your child brainstorm the tools or } \\
\text { supplies needed to complete the task. } \\
\text { (i.e., if we are starting a family garden, } \\
\text { what do we need to get started?) } \\
\text { - Downgrades: } \\
\circ \text { Take turns with your child! Work together } \\
\text { to complete more challenging tasks. } \\
\text { - Break larger activities into smaller pieces. } \\
\text { Practice the smaller pieces until that step } \\
\text { is mastered and then introduce the next } \\
\text { step. } \\
\text { - Demonstrate the activity for your child } \\
\text { before trying it together. }\end{array}$ \\
\hline
\end{tabular}

\section{PLAY}

\section{possible sensory} triggers:

- Activities can get noisy, especially when playing with siblings.

- Games and movement rich activities can get noisy and can make it difficult for a child to calm their body.

- Different toys and objects provide a variety of tactile input. Some tactile input that is non preferred can be dysregulating.

- Playrooms or play spaces full of toys, games, and swings can be visually overstimulatin

\section{How to foster the connection:}

- Follow your child's lead with play! Let them direct you and play in their theme. - If your child wants to play Disne princesses, let them choose wh princess you are and how to act.

- Remember that as an adult, you will get tired of an activity before your child will. Keep engaging in the game or activity with your child even if it seems repetitive.

- Use your words, gestures, and facia expressions to show your child that you're interested in their play. Praise your child, tell them that you're impressed with their new trick, that their game was so much fun, etc - Have fun, be silly, play, and participate alongside your child.

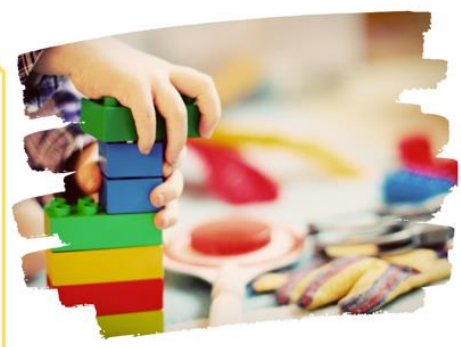

How to increase social connection:

- Askyour child questions about their game or activity. If they don't provide a role for you, ask questions.

- Who should I be

- How do I act like them?

- If your child assigns you a role, act like you forgot or don't know how to do it. Ask your child to show you or tell you again.

- If your child makes something out of blocks or legos, ask them to tell you about it. You can ask them questions for clarification (i.e., Where is the door to get inside the tower? Who lives here? etc.).

- Ask your child for their help. If they buit something, ask them if they can help you make one too.

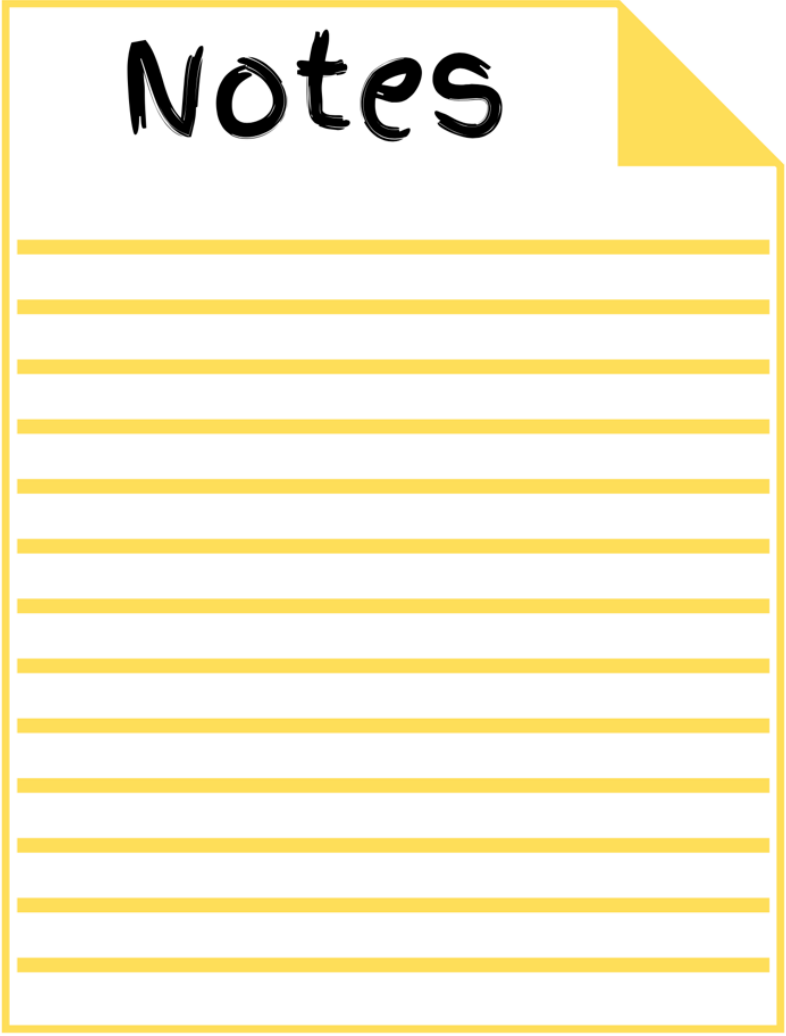

\section{PLAY}

\section{Activity ldeas}

Easy: cause and effect activities, minimal tools required, simple steps.

- Coloring, drawing, or painting

- Bubble popping game (parent blows bubbles, child pops them)

Medium: activities with few steps, requiring the use of a few different tools, some sequencing required

- Craft activities requiring a child to color, cut, and glue

- Stacking legos/blocks

- A game of tag

Hard: activities requiring sequencing, following and remembering directions, and planning.

- Pretend play activities with family members

- Obstacle cours

- Board games

- Making play dough/slime from scratch

\section{Skills being targeted:}

- Sequencing: completing a task with multiple

Steps. possibilities for movement. Walking, running jumping, climbing, throwing, catching, core

incorporated into play.

Fine motor skills: using your fingers for tasks. Tabletop tasks such as cutting, coloring. gluing, and building with legos are great ways

Opportunity for heavy work: carrying objects, pushing/puling objects, climbing, that an be incorporated into plapy Motor planning: the ability to proble

and carryout a plan to complete a movement (i.e. how to climb over, under, or through an object)
Upgrades \& downgrades:

- Upgrades:

- Have your child brainstorm an idea for game or obstacle course. Follow their lead, allowing them to be the teacher - See where your child's imagination takes them. Arts and crafts activity? What other things can they add or make to add to the activity?

- Downgrades:

- Take turns with your child! Work together to complete more challenging tasks. - Demonstrate the activity before having your child try it.

- Have other art supplies available for your child if they cannot grasp a pencil or marker (dot markers, jumbo crayons, etc.) 


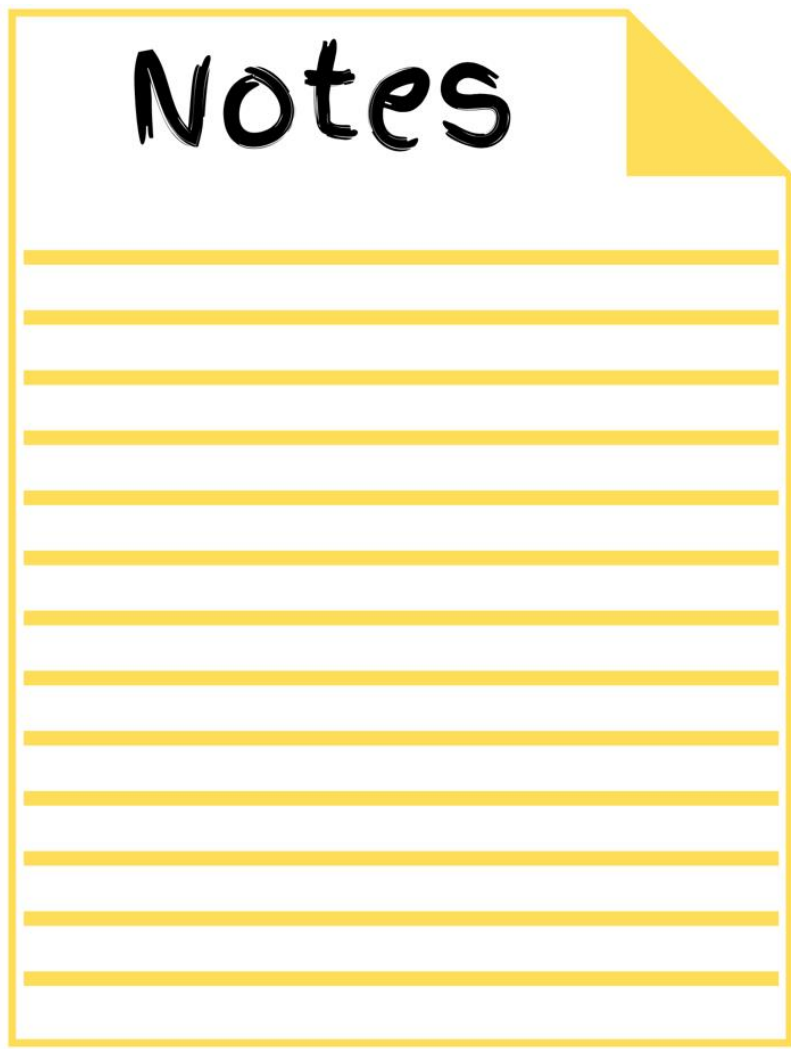

\section{SELF CARE}

\section{possible sensory \\ triggers:}

- Loud noises from the running water of

the sink, bathtub, or shower.

- The vibration of the electric toothbrush.

- The sensory input of clothes of different

textures, tags on clothes, water washing

over your head and face, toothbrush in

your mouth, comb, or brush running

through your hair.

- Smells and textures of shampoos

conditioners, body wash, bubble bath,

soap, etc.

\section{How to foster the} connection:

- Put on your child's favorite song, and you can complete your morning routine together!

- Put each family member's name in a bowl.

Take turns picking names out of the bowl. The

name you get is the person you are picking

out an outfit for. Outfits can be silly, or they

can be normal. It's up to youl

- Crazy hair day!

- The whole family can have matching crazy hair. Take turns doing each other's hair

- Complete a scavenger hunt to gather toys for bath time.

- Fill the bath tub up with bubbles and hide

toys under the bubbles. Without looking, take

turns guessing what toy you feel in your hands.

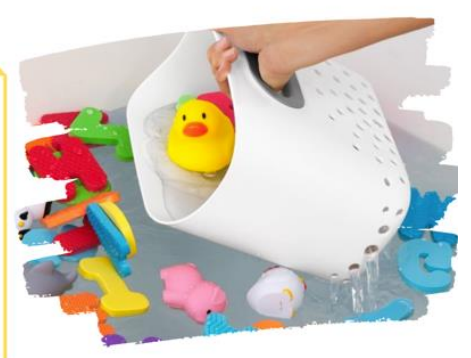

\section{SELF CARE}

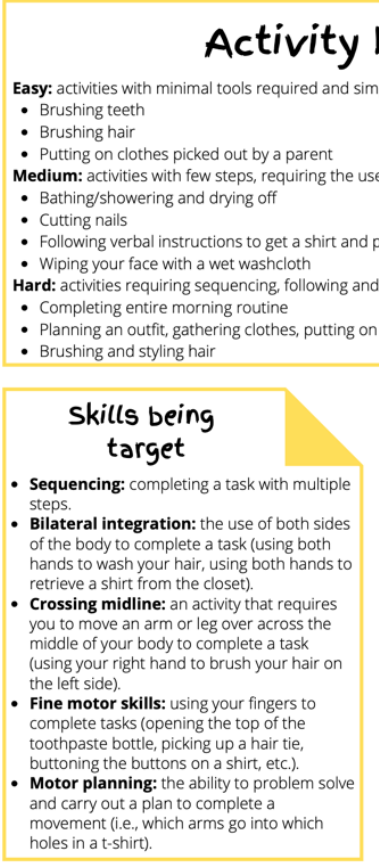

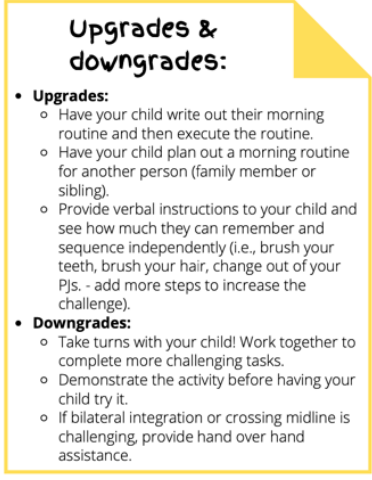

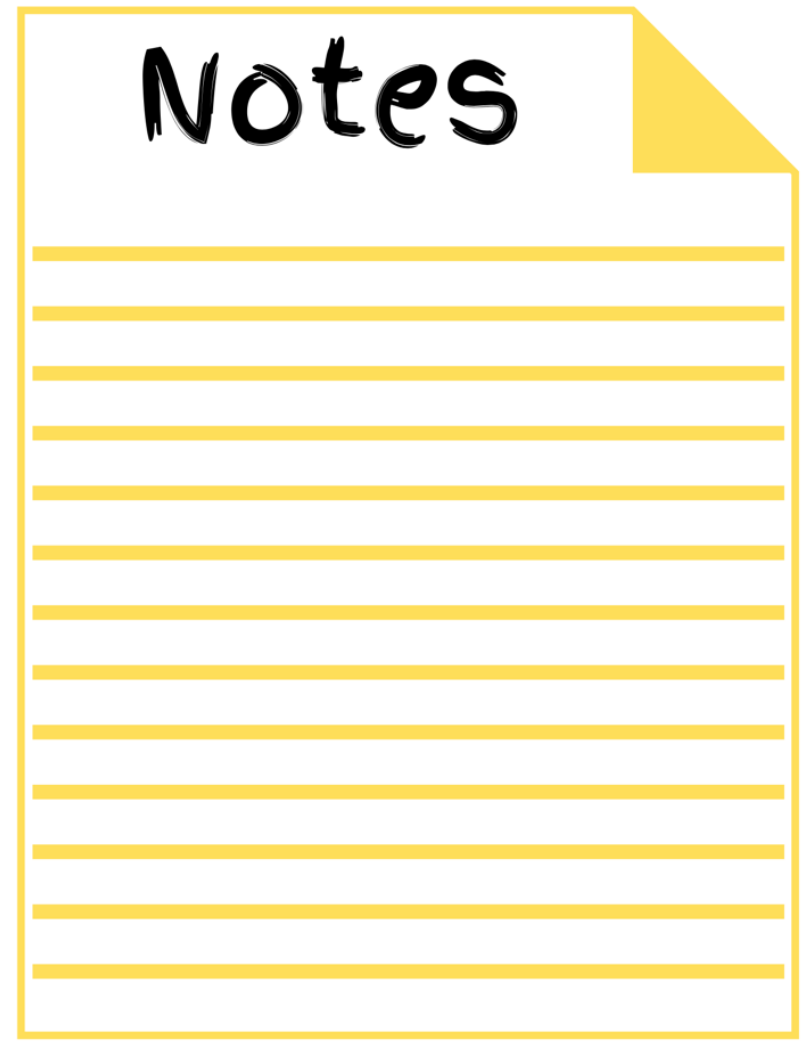

to increase

social connection:

- Ask your child what their favorite song is or what song they want to listen to.

- Brainstorm verbally or write down ideas for funny outfits. Parents and children will all take turns sharing ideas (i.e., pajama day, wear sunglasses in the house, put clothes on backwards, dress fancy while staying in the house).

- Ask your child questions about the outfit they

- Are you dressed as _ today? - Do you think you can find me a shirt that matches yours?

- Brainstorm verbally or write down ideas for crazy hair ideas (i.e., put three bows in your ari, use get to splke your hair up, wake up everyone, turn our hair blue, etc.). 


\section{INCLUDING SIBLINGS}

Not only is the parent and child
relationship important, but the sibling
relationship is just as important. When
completing activities, encourage all
children to participate. When possible,
try to provide challenges to your
children and see if they can work
together and problem solve together.
Below are a few activity ideas of ways

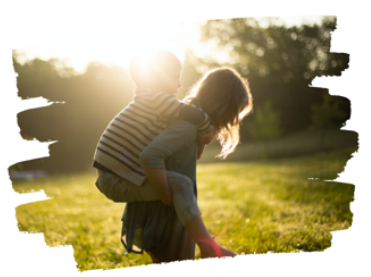

to include siblings in play!

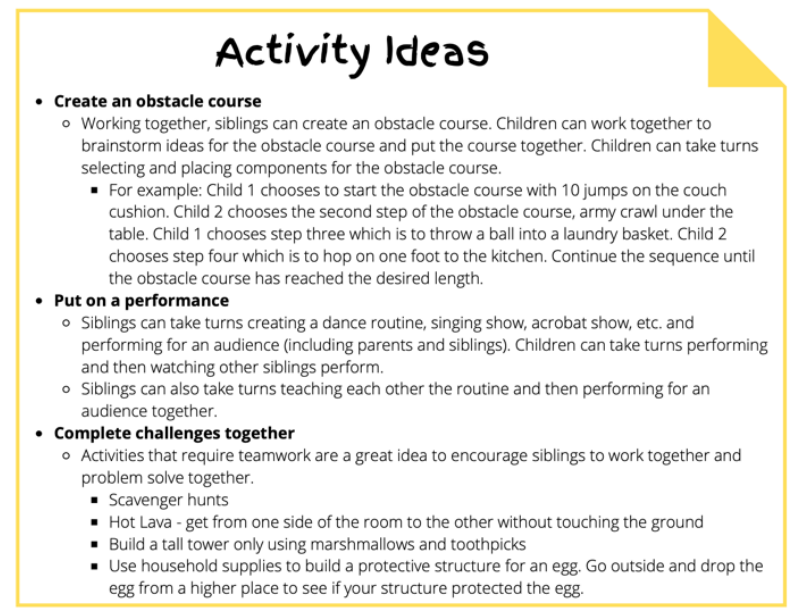

\section{EMOTIONS}

Research has shown that children who have experienced childhood trauma often experience challenges when it comes to handling their emotions (AOTA, 2015). It is important to validate the emotions of a child and encourage them to share their feelings with you. You can start by sharing your feelings with your child and then invite them to share their feelings with you. Children may not always be open to or willing to sharing their emotions or feelings, but getting the dialoge started is a great first step.

There are tools that can be used to help a child understand and identify their emotions. Below are a few resources that can be used but there may be other programs and strategies that can also be used.

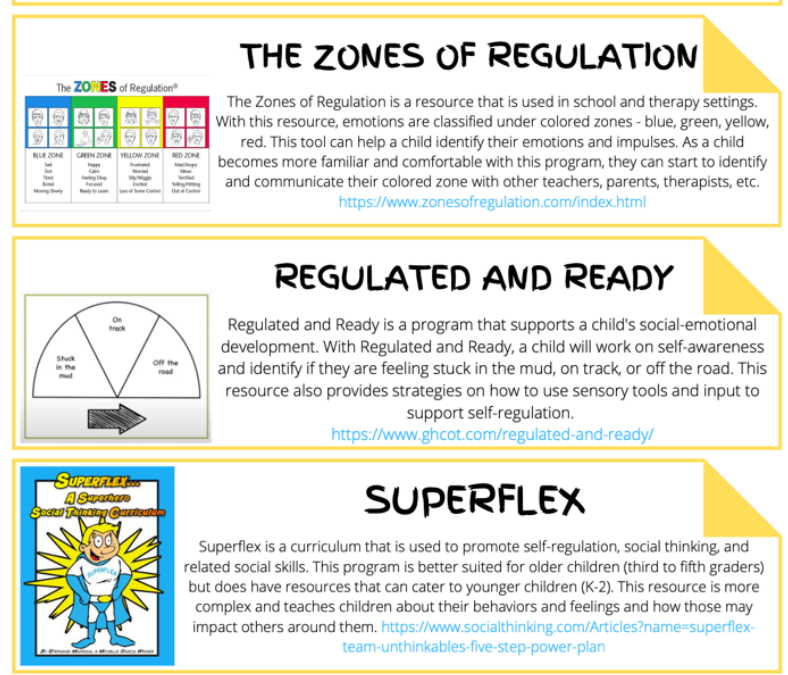




\section{REFERENCES}

American Occupational Therapy Association. (2015). Childhood trauma.

https://www.aota.org/ /media/Corporate/Files/Practice/Children/Childhood-Trauma-Info-Sheet-

2015.pdf

Kid Sense. (2020). Fine motor skills.

https://childdevelopment.com.au/areas-of-concern/fine-motor-skills/

Kid Sense. (2020). Gross motor skills.

https://childdevelopment.com.au/areas-of-concern/gross-motor-skills/

Liu, C., Chen, X., Song, P., Lu, A., Wang, L., Zhang, X., \& Huang, Z. (2018).

Relationship between childhood emotional abuse and self-esteem: A dual mediation model of attachment. Social Behavior \& Personality: An International Journal, 46(5), 793

800. https://doi.org/10.2224/sbp. 6655

Malek, C. S. (2011, December). Understanding the unique needs of children in foster

care. https://www.ohelfamily.org/?q=content/understanding-unique-needs-children-foster-care

Middletown Centre for Autism. (2020). Strategies according to sense

https://sensory-processing.middletownautism.com/sensory-strategies/strategies-according-to-sense/

Paris, B. \& Murray-Slutsky, C. (n.d.). Self-regulation: What is it? And what does sensory

processing have to do with it?

https://www.southpaw.com/self-regulation-what-is-it-and-what-does-sensory-processing-have-to-do-

with-it

Profectum. (2018). What is the developmental, individual difference, relationship-based model

and why is it important?

https://profectum.org/about/dir/ 


\section{Appendix C - Logic Model}

Program: Play Based Program for Children in Foster Care - Logic Model

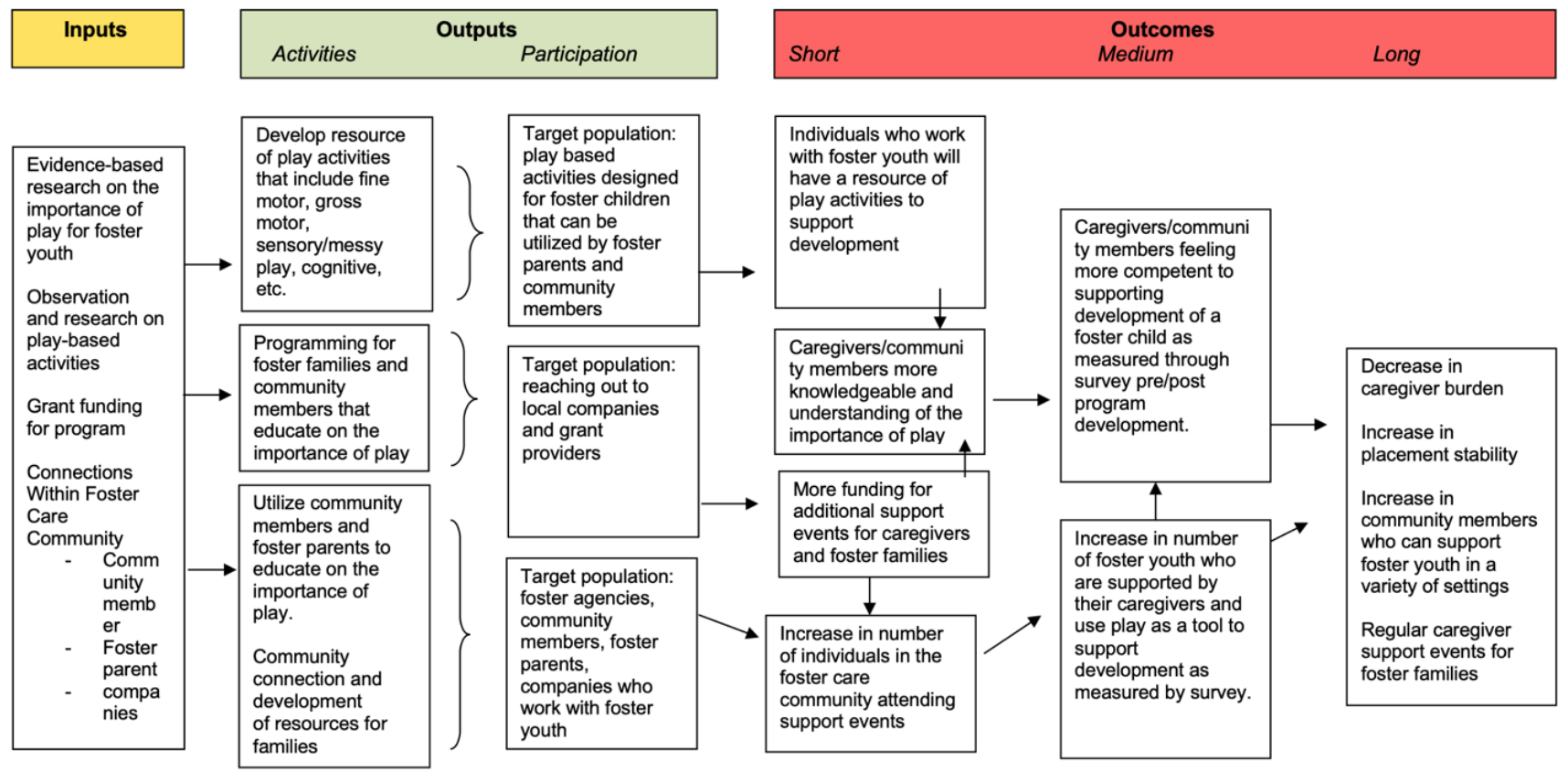

Assumptions

- Foster care community (foster parents, caregivers, community members, etc.) wants regular support events

- Foster care community does not have adequate training to support the development of foster youth

External Factors

- Legislation changes can influence need for grant funding

- Availability of grant funding

- Existing training for foster care community 


\section{Appendix D - Sample Interview Questions for Adoptive and Foster Families}

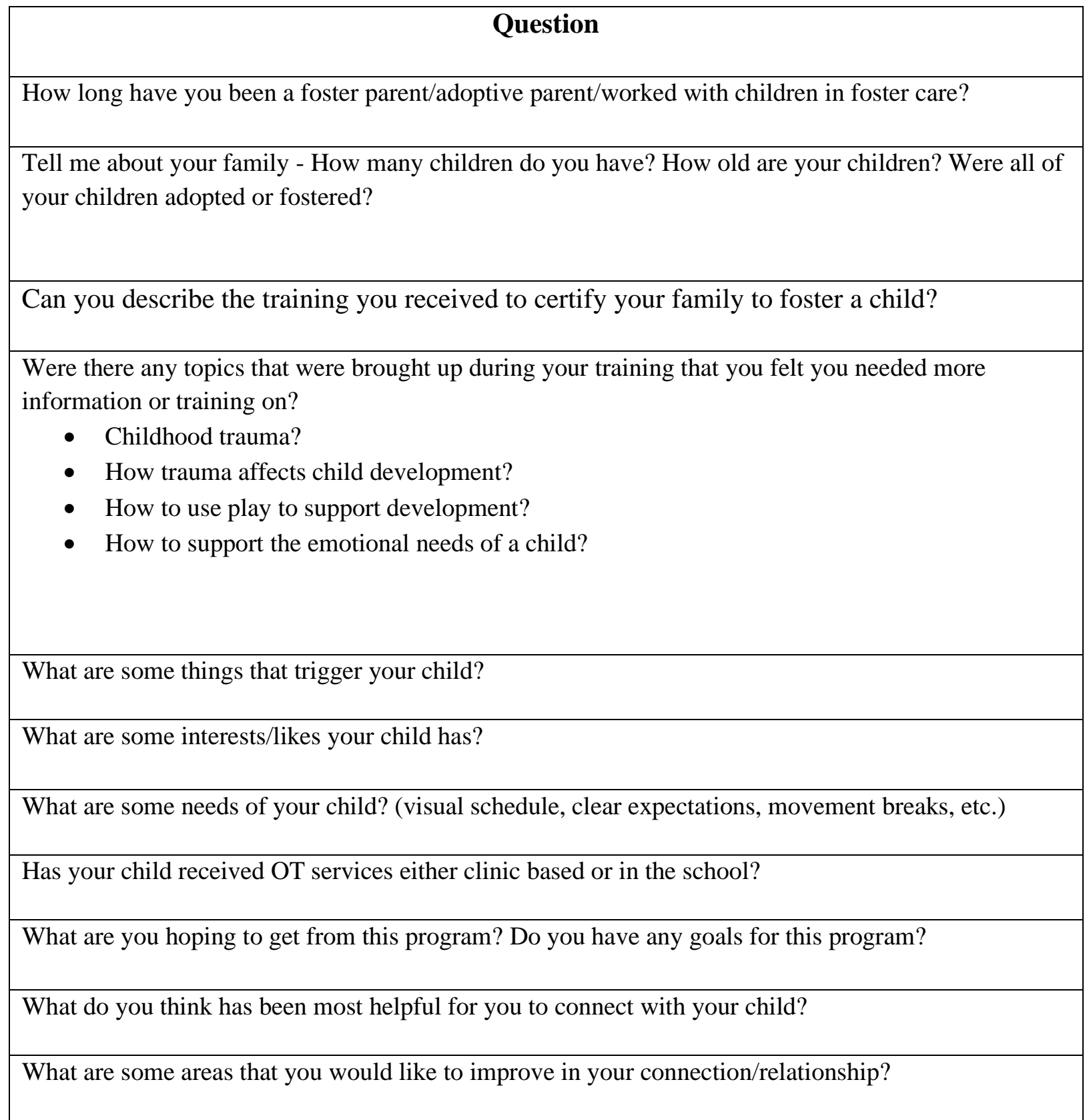

